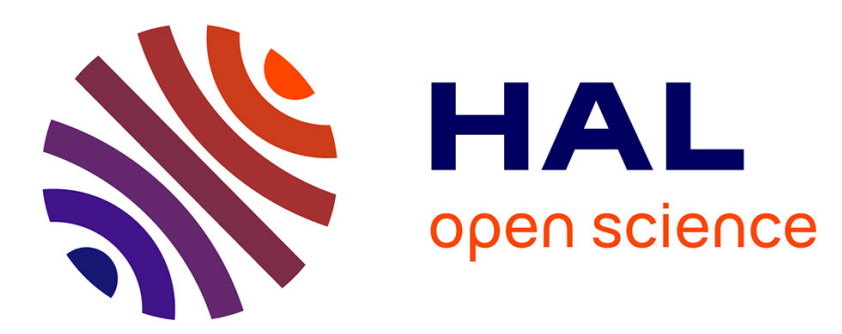

\title{
Enquête autour des lames tranchantes de l'Azilien ancien. Le cas du niveau inférieur du Closeau (Rueil-Malmaison, Hauts-de-Seine, France)
}

Pierre Bodu, Ludovic Mevel

\section{- To cite this version:}

Pierre Bodu, Ludovic Mevel. Enquête autour des lames tranchantes de l'Azilien ancien. Le cas du niveau inférieur du Closeau (Rueil-Malmaison, Hauts-de-Seine, France). L'anthropologie, 2008, 112, pp.509 - 543. 10.1016/j.anthro.2008.06.004 . hal-03391650

\author{
HAL Id: hal-03391650 \\ https://hal.science/hal-03391650
}

Submitted on 10 Dec 2021

HAL is a multi-disciplinary open access archive for the deposit and dissemination of scientific research documents, whether they are published or not. The documents may come from teaching and research institutions in France or abroad, or from public or private research centers.
L'archive ouverte pluridisciplinaire HAL, est destinée au dépôt et à la diffusion de documents scientifiques de niveau recherche, publiés ou non, émanant des établissements d'enseignement et de recherche français ou étrangers, des laboratoires publics ou privés. 
Article original

\title{
Enquête autour des lames tranchantes de l'Azilien
} ancien. Le cas du niveau inférieur du Closeau (Rueil-Malmaison, Hauts-de-Seine, France)

\section{Investigation around sharp blades from the early Azilian. Study case of Le Closeau lower level (Rueil-Malmaison, Hauts-de-Seine, France)}

\author{
Pierre Bodu ${ }^{\mathrm{a}}$, Ludovic Mevel ${ }^{\mathrm{b}, *}$ \\ ${ }^{a}$ UMR 7041 du CNRS, équipe d'ethnologie préhistorique, MAE, Maison René-Ginouvès, \\ 21, allée de l'Université, 92023, Nanterre cedex, France \\ ${ }^{\mathrm{b}}$ UMR 7055 du CNRS, université Paris-10 Nanterre, laboratoire préhistoire et technologie, \\ MAE, Maison René-Ginouvès, 21, allée de l'Université, \\ 92023, Nanterre cedex, France
}

Disponible sur Internet le 10 juillet 2008

\section{Résumé}

Bien que support très majoritaire de l'outillage du Paléolithique supérieur, la lame est rarement considérée comme un outil à part entière. Le plus souvent, l'esquillement de ses bords, s'il n'est pas considéré comme accidentel, permet tout au plus de la classer dans la catégorie des lames retouchées, dont l'homogénéité morphologique, dimensionnelle et fonctionnelle est plus que douteuse. Dans certains cas cependant, la qualité et la récurrence des retouches qui aménagent les bords font de la lame ainsi aménagée, un outil spécifique au même titre que les grattoirs ou les burins qui l'accompagnent. C'est le cas des fameuses pointes à face plane du Solutréen ancien qui ne sont vraisemblablement que des lames couteaux. Les lames à retouches écailleuses et écailleuses scalariformes de l'Azilien ancien, moins célèbres, sont pourtant tout aussi caractéristiques d'un mode d'avivage particulier des tranchants au cours de cette courte période du Tardiglaciaire.

(C) 2008 Elsevier Masson SAS. Tous droits réservés.

\footnotetext{
* Auteur correspondant.

Adresse e-mail : ludomevel@yahoo.fr (L. Mevel).
} 


\begin{abstract}
Although a major blank of the Upper Palaeolithic toolkit, the blade is rarely considered as a tool by itself. Most of the time, the scar of its edges, if not considered accidental, permits at the most to class it in the category of retouched blades, whose morphological, metric and functional homogeneity remain doubtful. In some cases, however, the quality and recurrence of the edge's retouches, make of the blade thus retouched, a specific tool as are the end-scrapers or burins that accompany it. Such is the case with the famous points with plane face of the early Solutrean that are seemingly just knife blades. The lesser known blades with scaled retouches and with scaled and stepped retouches from the early Azilian are also characteristic of a particular mode of sharpening for cutting edges during this short Late Glacial period.
\end{abstract}

(C) 2008 Elsevier Masson SAS. Tous droits réservés.

Mots clés : Lame à retouches écailleuses scalariformes ; Lame utilisée ; Approche fonctionnelle ; Azilien ancien ; Bassin parisien ; Le Closeau

Keywords: Blade scaled and stepped retouches; Use blade; Functional study; Early Azilian; Paris basin; Le Closeau

\title{
1. Introduction
}

Typologiquement, la lame tranchante du Paléolithique supérieur est placée dans une catégorie large, aux contours flous qui masque la diversité de ce type d'objets tant en termes de fabrication et d'affûtage qu'en termes de fonction. Cette catégorie est d'ailleurs à ce point mal définie qu'elle ne constitue pas la plupart du temps un groupe à part entière dans la liste typologique classique. La lame tranchante, véritable pivot de l'économie préhistorique est placée au mieux dans les « lames retouchées », au pire dans les « divers ». La raison de cet ostracisme, est sans doute liée à notre difficulté à définir ce qui, dans les lames retouchées, est d'ordre intentionnel ou accidentel. Un effort de précision doit donc être apporté à la définition de cette (ces) catégorie(s) d'objet(s) qui s'appuierait certes sur des résultats tracéologiques, mais qui prendrait également en compte des données intrinsèques (dimensions, morphométrie) et plus généralement contextuelles.

La découverte et la fouille du Closeau (Rueil-Malmaison, Hauts-de-Seine) entre 1994 et 2000 (Fig. 1, Bodu, 1998b ; Bignon et Bodu, 2006 ; Bodu et al., 2006a) ont été l'occasion d'interroger de façon plus approfondie les « couteaux » de silex et plus particulièrement ceux du niveau azilien ancien dont l'aspect le plus particulier est le caractère de la retouche, une retouche rasante. Ces objets, si l'on en croit la littérature peu abondante sur le sujet, semblent fréquents, voire peut-être exclusifs de l'Azilien ancien au sein du Tardiglaciaire (Pion et al., 1990 ; Valentin in Chollet et Dujardin, 2005). Un rapide retour en arrière nous montre, en effet, que les lames à retouches rasantes de l'Azilien ancien sont absentes du Magdalénien (Bodu et al., 2006b ; Leroi-Gourhan et Brézillon, 1966, 1972 ; Schmider, 1971). Lorsqu'il est fait état de lames retouchées dans certains gisements magdaléniens supérieurs du sud-ouest, par exemple, ces retouches sont décrites comme courtes et menues (Sonneville-Bordes, 1960 : p. 469). Elles ne sont pas plus mentionnées dans l'Azilien récent, que ce soit dans une phase intermédiaire de l'Alleröd ou dans une phase plus récente (Fagnart et Coudret, 2000 ; Bodu, 1998a, 1998b), où les couteaux à dos pourraient bien les avoir remplacées (Fig. 2). En revanche, on retrouve l'idée de la lame-couteau affûtée dans certaines séries protomagdaléniennes et aurignaciennes (Bricker, 1995 ; Mouton et Joffroy, 1957), mais aussi dans le Solutréen, et ce, dans des domaines géographiques variés (Foucher et Normand, 2004) (Fig. 3). 


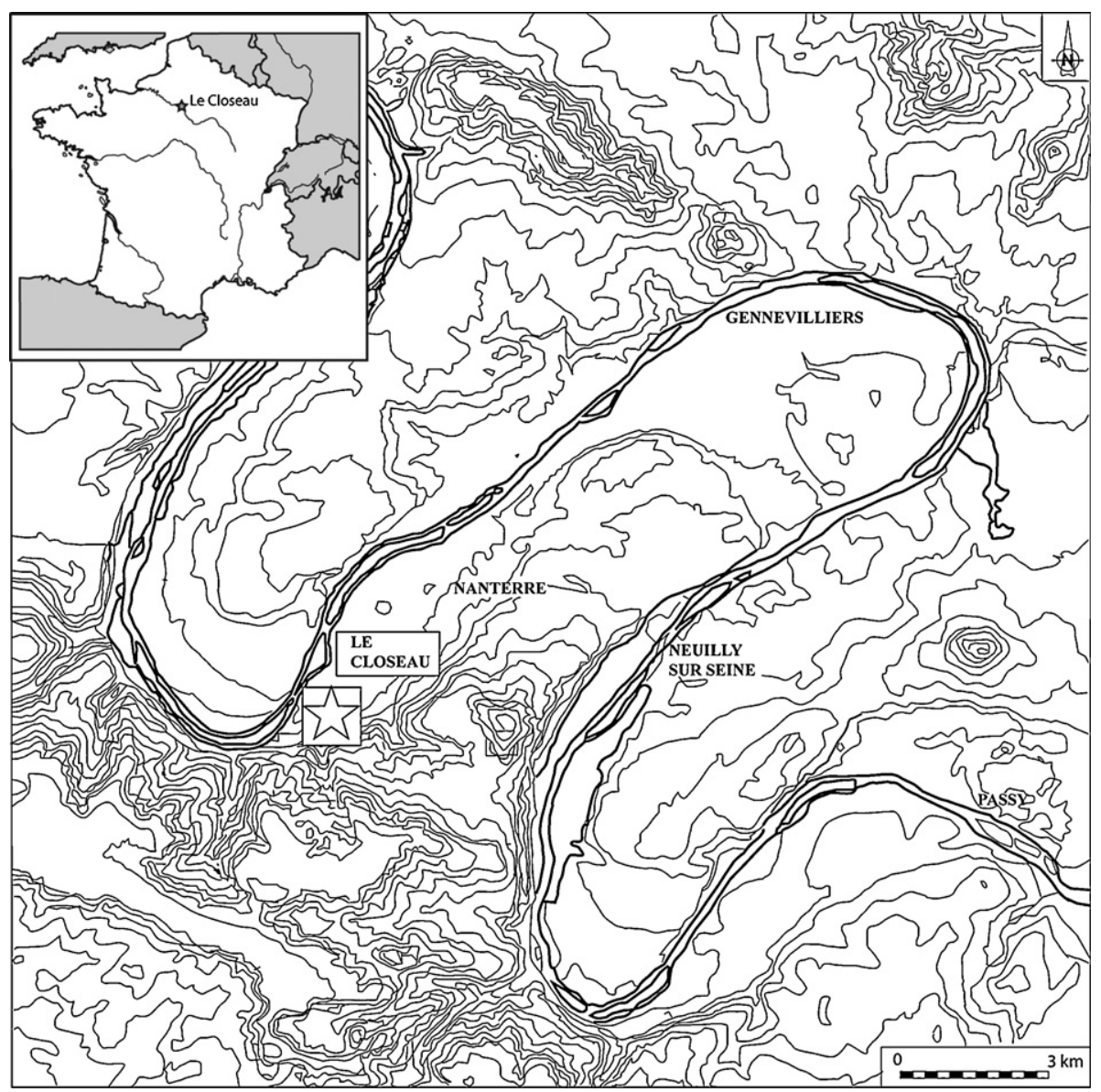

Fig. 1. Localisation du site du Closeau (Hauts-de-Seine).

Location of Le Closeau (Rueil-Malmaison - Hauts de Seine) in the Paris region.

À la suite d'un certain nombre de travaux réalisés sur les lames du Closeau (Christensen in Bodu, 1995, 1998b ; Mevel, 2003), nous avons développé une démarche expérimentale afin de mieux comprendre l'origine et la vocation des enlèvements visibles sur un grand nombre d'entre elles. Dans le cadre du vaste rapport de synthèse de fouille (Bodu, 1998b), nous avions évoqué l'hypothèse d'une retouche rasante obtenue par percussion tendre lors de l'affûtage des tranchants des lames. Par le biais de cette démarche expérimentale, nous avons souhaité tester cette hypothèse.

\section{Le contexte}

Au Closeau, le niveau de l'Azilien ancien couvre une surface d'environ $1000 \mathrm{~m}^{2}$ (Fig. 4). Il a livré sept locus parmi lesquels deux (le locus 4 et le 46) correspondent à de véritables unités d'occupation aux activités multiples. Tous sont situés au nord du site, la plupart étant localisés au-delà d'une butte de graviers qui cerne le chenal où ont été fossilisés les locus des niveaux 


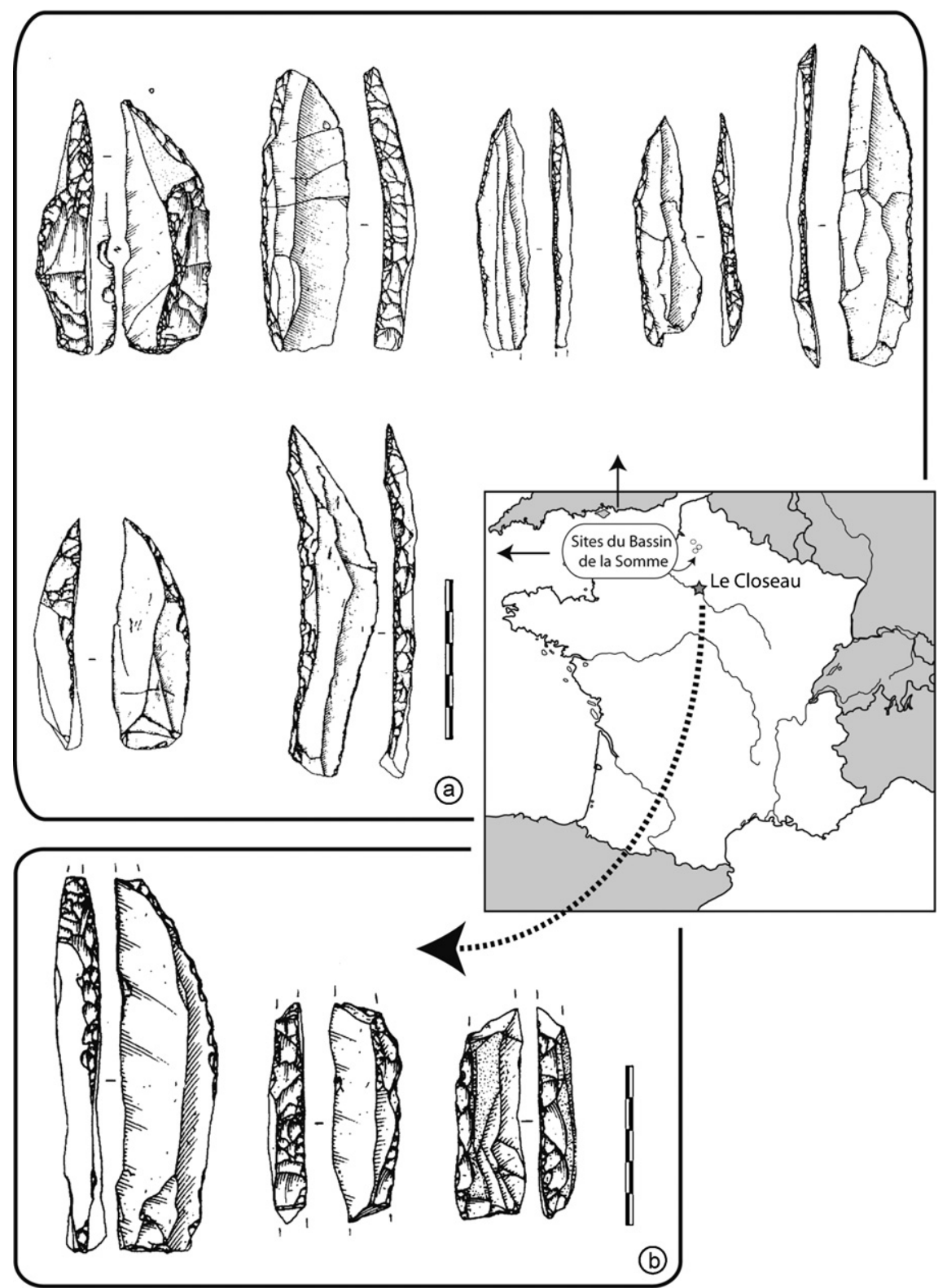

Fig. 2. Quelques couteaux à dos de l'azilien récent. a. Différentes lames à dos provenant des sites du Bassin de la Somme (d'après Fagnart et Coudret, 2000). b. Lames à dos du niveau intermédiaire du Closeau - Locus 51 (d'après Bodu, $1998 \mathrm{a}$, 1998b) (Dessins : Ph. Alix).

Late Azilian backed blades. a. Different blades coming from sites of the Somme basin (after Fagnart and Coudret, 2000). b. Blades of the intermediate level from Le Closeau - locus 51 (after Bodu, 1998a, 1998b) (drawing: Ph. Alix). 


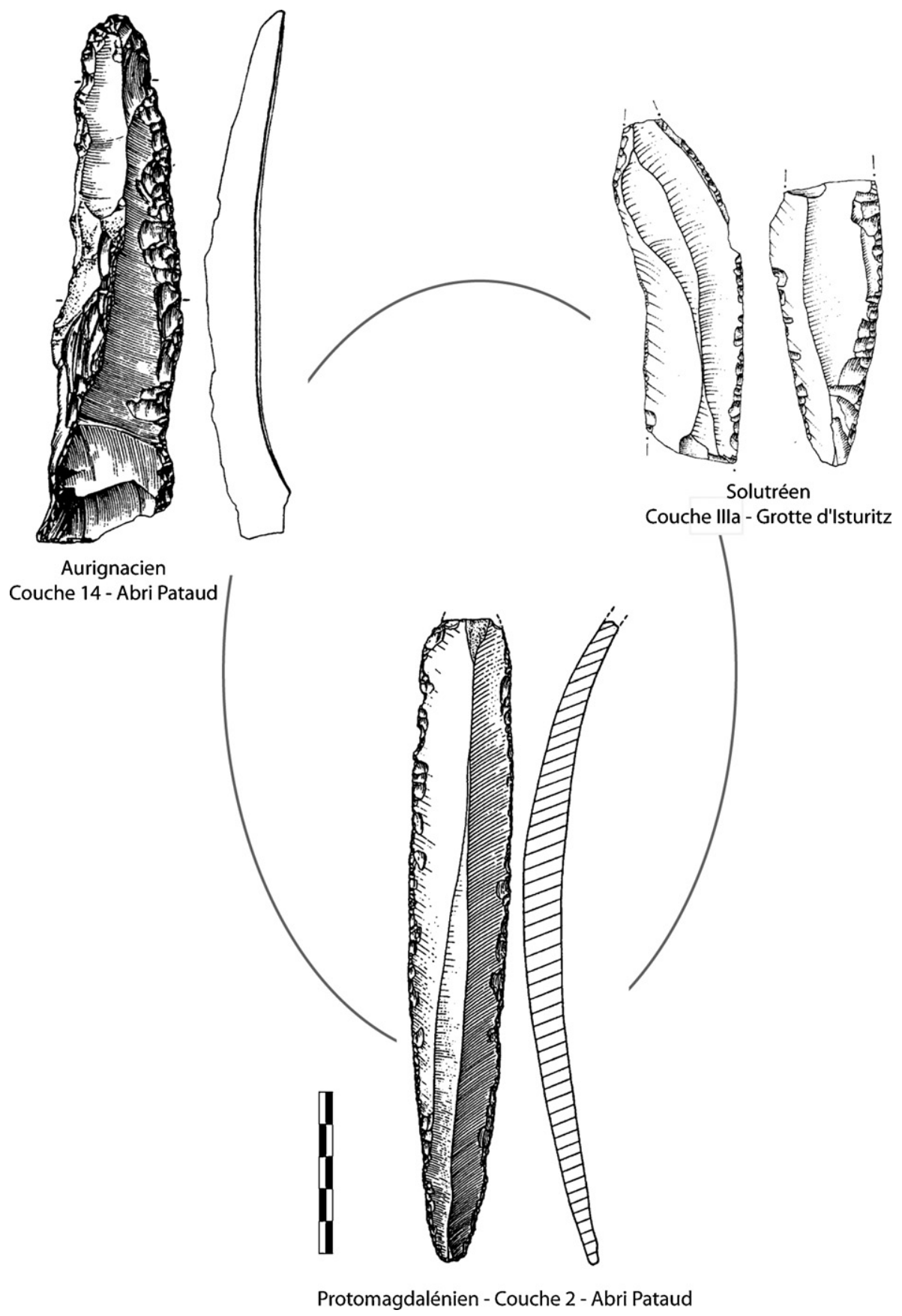

Fig. 3. Diverses lames à retouches écailleuses du Paléolithique supérieur ancien (Abri Pataud, d'après Bricker, 1995 : p. 80 et 176 ; Grotte d'Isturitz, d'après Foucher et Normand, 2004 : p. 95).

Blades with scaled retouches from the early Upper Palaeolithic (Abri Pataud from Bricker, 1995: p. 80 and 176; Grotte d'Isturitz from Foucher and Normand, 2004: p. 95). 


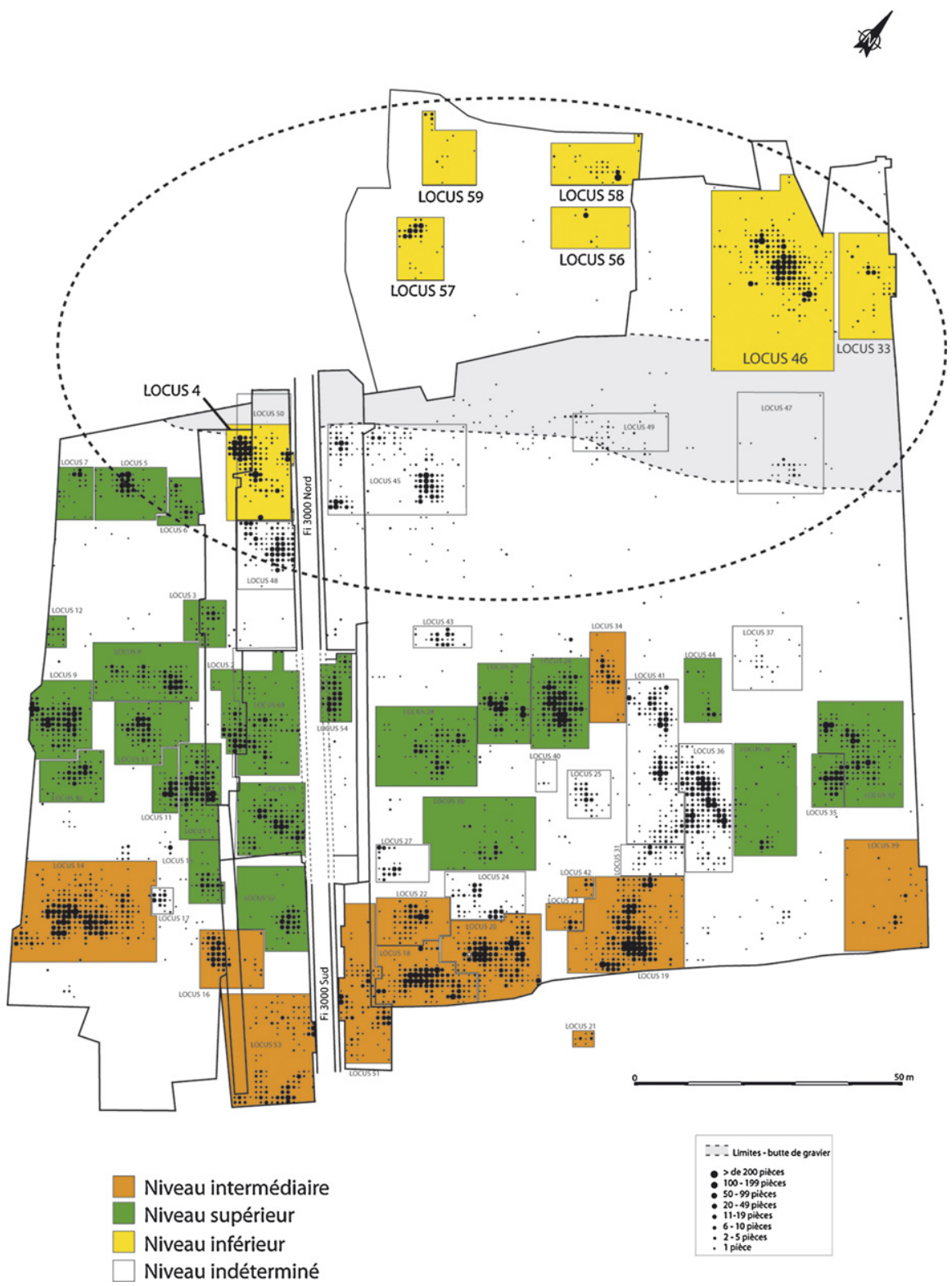

Fig. 4. Plan des locus des différents niveaux aziliens du Closeau. (Plan : N. Gomes, I. Pasquier). Map of Le Closeau site's loci. (Drawing: N. Gomes, I. Pasquier).

aziliens plus récents. Un seul, le locus 4 se trouve en bordure de ce chenal. Il a apparemment été recouvert plus tardivement par les inondations comme en témoigne le plus fort état de patine observable sur les pièces lithiques (Bodu, 1998b).

Les deux locus principaux (le 4 et le 46) concentrent l'essentiel du matériel lithique (taillé et non taillé) et des vestiges osseux. C'est dans ces deux locus que les lames retouchées sont les plus nombreuses, associées ou non à un autre type d'outil (220 objets) (Tableau 1). C'est également 
Tableau 1

Corpus des lames pris en compte dans l'étude

Blades included in the study

\begin{tabular}{lllllr}
\hline Locus & $\begin{array}{l}\text { Grattoirs - lames } \\
\text { retouchées }(n,[\%])\end{array}$ & $\begin{array}{l}\text { Grattoirs - lames à enlèvements } \\
\text { marginaux }(n,[\%])\end{array}$ & $\begin{array}{l}\text { Lames à enlèvements } \\
\text { marginaux }(n,[\%])\end{array}$ & $\begin{array}{l}\text { Lames retouchées } \\
(n,[\%])\end{array}$ & $\begin{array}{c}\text { Total } \\
4\end{array}$ \\
\hline 33 & $9,[4,5]$ & $5,[2,5]$ & $42,[21,3]$ & $35,[17,7]$ & 91 \\
46 & $3,[2,5]$ & & $27,[65]$ & $1,[2,4]$ & 29 \\
& $3,[1,5]$ & $3,[1,5]$ & $65,[31]$ & $58,[28]$ & 129 \\
& & & 249 \\
\hline
\end{tabular}

autour de ces grands locus que l'on observe un fort appareillage de blocs de pierre destinés vraisemblablement à caler des éléments d'une superstructure. Autour de ces deux unités s'articulent cinq locus plus ténus en termes de quantités de vestiges et de densité de l'occupation des sols (locus 33, 56, 57, 58, 59) (Bodu, 1998b).

Des remontages d'éléments de silex (Bodu et al., 2006a) montrent d'évidentes relations entre certaines de ces unités, que l'on peut interpréter différemment, même si l'idée de la complémentarité entre elles, y compris entre les deux plus gros locus, est envisageable. Pour l'heure l'emprunt par le locus 46 de supports débités auprès de l'unité 4 semble être totalement avéré. De même, les locus annexes ont apparemment bénéficié de lames taillées dans l'une des deux grandes unités, le locus 46 (Fig. 5).

La faune chassée est dominée par le cheval (67\% NRD), la présence du cerf (24,7\% NRD) et du sanglier (3,4\% NRD) étant moins importante (Bemilli, 2000). Les études de saisonnalité font

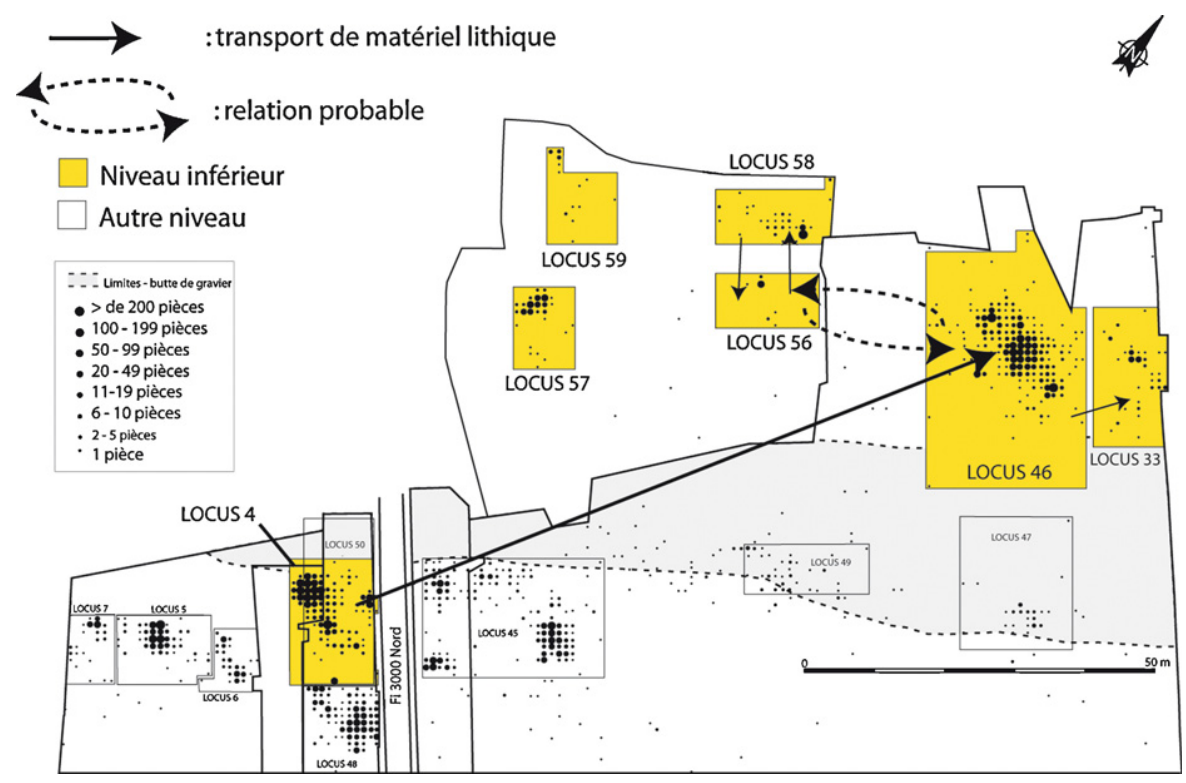

Fig. 5. Remontages du matériel lithique entre les locus du niveau azilien ancien du Closeau (DAO : G. Debout). Refitting of the lithic material among the different lower level loci of Le Closeau (CAD: G. Debout). 
état d'une occupation du site durant toute l'année en tout cas pour le locus 46 , car pour le locus 4 les indices de saisonnalité sont plus ténus (Bignon, 2000 ; Bignon et Bodu, 2006 ; Bodu et al., 2006a). Dans le locus 46, des animaux ont été abattus essentiellement au printemps, dans une moindre mesure en automne et en hiver et beaucoup moins en été. Le lieu semble avoir été propice à des chasses abondantes.

Cependant, la faible quantité de matériel lithique abandonné dans chacun des grands locus, un outillage classique numériquement faible où les grattoirs $(51 \%)$ et les pointes à dos
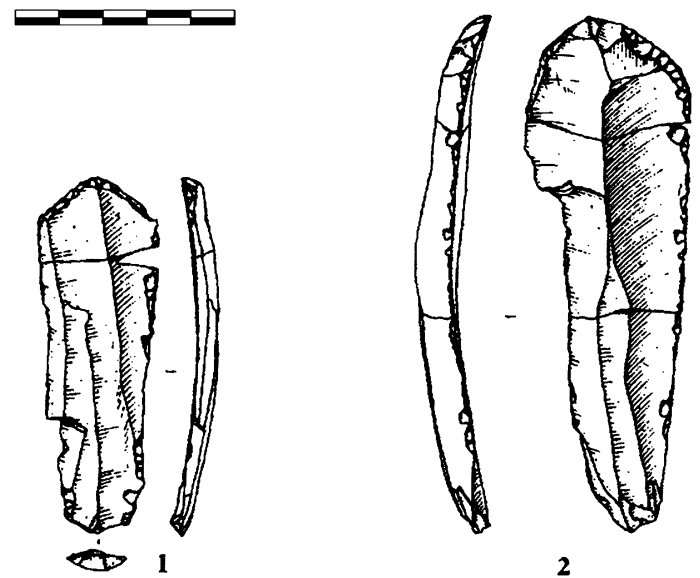

2

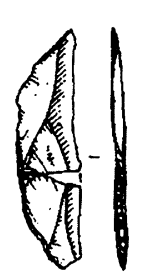

4

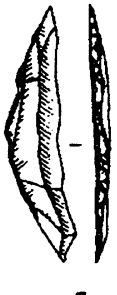

5

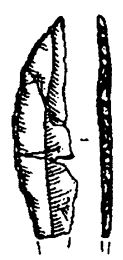

6

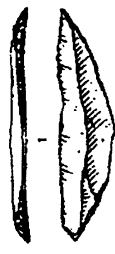

7

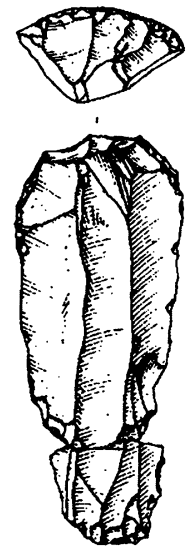

3

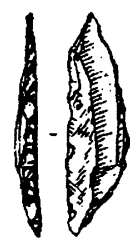

8
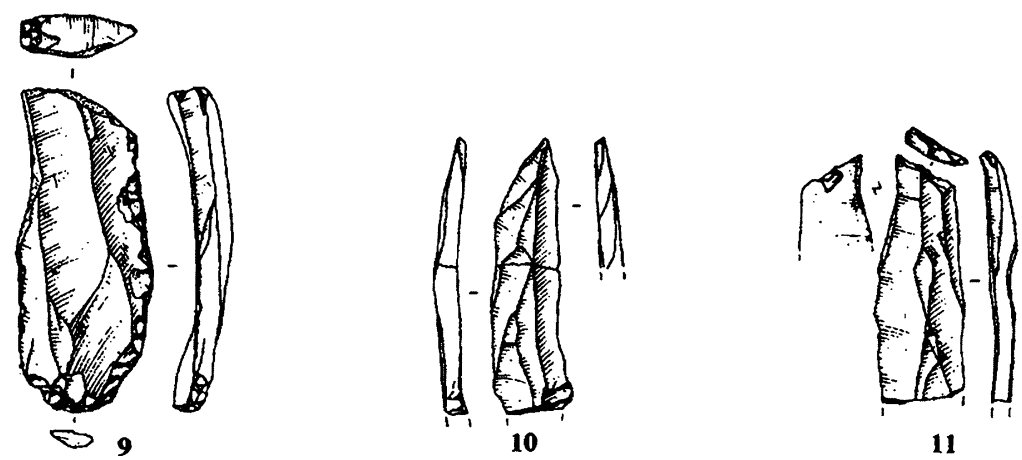

Fig. 6. Principales catégories d'outils lithiques du niveau azilien ancien du Closeau. 1-3 : grattoirs ; 4-8 : bipointes ; 911 : burins (dessins : Ph. Alix).

Main tools from early Azilian level of Le Closeau. 1-3: end-scrapers; 4-8: projectile points; 9-11: burins (drawing: Ph. Alix). 
Tableau 2

Le Closeau, niveau inférieur. Datations ${ }^{14} \mathrm{C}$ de la faune

Le Closeau, low level. Radiocarbon dating of faunal remains

\begin{tabular}{|c|c|c|c|c|}
\hline Locus & Détermination & $\mathrm{N}^{\mathrm{o}}$ datation & Résultats BP & Calibration BC \\
\hline 4 & Phalange sanglier & Gra 18701 & $5380 \pm 100$ & 4446 à 3977 \\
\hline 4 & Diap. os long sanglier & Gra 18762 & $11640 \pm 70$ & 11868 à 11507 \\
\hline 4 & Phalange sanglier & Gra 18697 & $10240 \pm 150$ & 10826 à 9311 \\
\hline 4 & Diap. esp. indéterminée & OxA 5680 (Lyon 166) & $12090 \pm 90$ & 12511 à 11846 \\
\hline 4 & Diap. esp. indéterminée & OxA 6338 (Lyon 313) & $12050 \pm 100$ & 12474 à 11785 \\
\hline 33 & Frgt diap. Esp. taille moy. & Gra-10892 (Lyon-814) & $9200 \pm 70$ & 8373 à 8077 \\
\hline 33 & Frgt diap. Métap. cheval & Néant & & \\
\hline 33 & Phalange boviné & Gra 18815 & $12480 \pm 70$ & 13305 à 12361 \\
\hline 33 & Diap os long cheval & Gra 18860 & $12510 \pm 80$ & 13361 à 12366 \\
\hline 46 & Frgt tibia cheval & GrA-11664 (Lyon-789) & $12350 \pm 60$ & 12836 à 12191 \\
\hline 46 & Frgt fémur cervidé & GrA-11665 (Lyon-790) & $12360 \pm 60$ & 12850 à 12203 \\
\hline 46 & Frgt fémur sanglier & Gra 18816 & $12350 \pm 70$ & 13114 à 12191 \\
\hline 46 & Frgt fémur sanglier & Gra 18763 & $6420 \pm 110$ & 5612 à 5083 \\
\hline 46 & Sanglier & AA41881[1] & $12423 \pm 67$ & \\
\hline 46 & Métacarpe 5 droit Lion & AA41882[2] & $12248 \pm 66$ & \\
\hline 56 & Radius droit cervidé & Gra 18819 & $12340 \pm 70$ & 12423 à 12816 \\
\hline
\end{tabular}

(34\%) dominent le corpus (Fig. 6), mais aussi un nombre limité d'animaux abattus ${ }^{1}$ (14 individus pour le 46 ; sept individus pour le 4, trois individus pour le 33 ) militent plus en faveur de passages successifs qu'ils n'indiquent une occupation unique durant toute l'année. Selon Olivier Bignon (Bignon, 2000 ; Bodu et al., 2006a), la composition faunique des locus 4, 46 et 33 serait le résultat de chasses de type attritionnel correspondant à des traques d'animaux isolés. Elle évoquerait moins les chasses collectives avec de grands abattages comme cela est connu pour un grand nombre de gisements magdaléniens du Bassin parisien (Bignon et al., 2006).

Parmi les 17 dates tentées sur le niveau ancien (Tableau 2), cinq sont à l'évidence trop jeunes, et deux n'ont rien donné. Les dix autres placent l'occupation du Closeau au sein du Bölling (entre $12500 \mathrm{BP}$ pour les plus anciennes et $12000 \mathrm{BP}$ pour les plus récentes). S'il faut se méfier du phénomène du plateau, les arguments géomorphologiques de Christine Chaussé semblent, quant à eux, bien confirmer l'hypothèse de rattachement du sol d'occupation au Bölling (Chaussé, 2005). On notera, à propos des dates obtenues pour le locus 4 et pour les locus 46 et 33, qu'elles sont distantes de près de 300 à 400 ans. Que penser alors des remontages de silex qui témoignent à l'évidence de relations entre ces trois unités ?

\section{Le corpus étudié}

Sur les 5000 pièces lithiques taillées retrouvées sur le niveau inférieur, seuls ont été pris en compte dans cette étude 249 produits laminaires portant les vestiges d'une retouche intentionnelle (Tableau 1), accidentelle ou potentiellement d'utilisation. Pour peaufiner les

\footnotetext{
${ }^{1}$ Dans le gisement magdalénien de Pincevent, une grande unité d'occupation à double foyers (V105-T112, section 36), a livré les restes de près de 40 rennes, alors qu'il s'agit incontestablement de campements saisonniers (Leroi-Gourhan et Brézillon, 1972).
} 


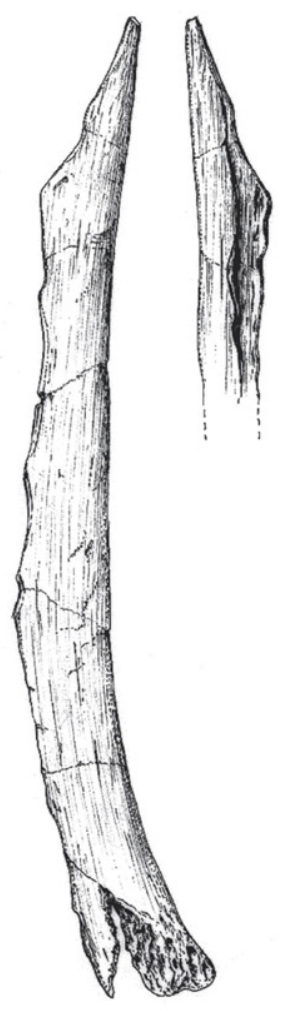

(a)

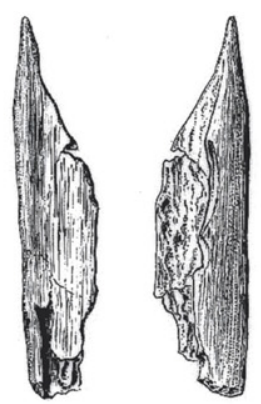

(b)

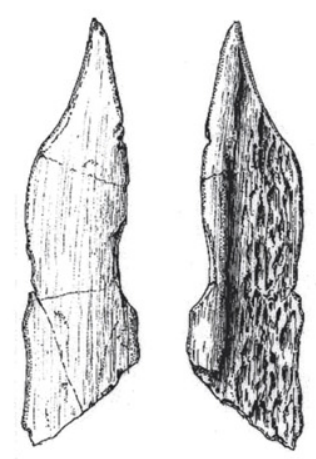

(c)

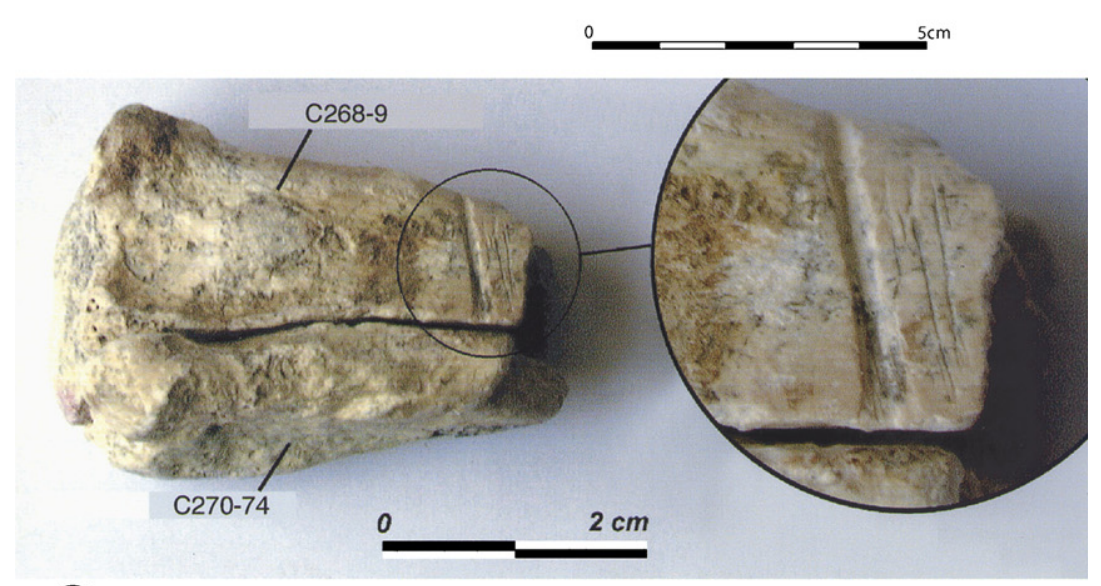

(d)

Fig. 7. Industrie en os du niveau inférieur du Closeau : a-c. Trois poinçons en os sur côte d'herbivore (dessins : D. Molez) ; d. Métacarpien de lion (Panthera spelaela) scié (cliché : Th. Argant).

Bone industries from the early Azilian level of Le Closeau. a-c. Three bone awls on ribs of large ungulates (drawing: D. Molez). d. Sawing marks on a lion's (Panthera spelaela) metacarpal (prox parts) (Photo: Th. Argant). 
comparaisons, nous y avons ajouté une cinquantaine de lames présumées brutes. En tout, cela représente environ $5 \%$ du total de l'industrie lithique taillée des locus 4, 46 et 33 .

L'état de fraîcheur du matériel est ici exceptionnel et il est important de préciser que l'on n'a pas identifié de différences de patine entre le (les) bords retouché(s) et ou utilisé(s) et le reste du support. Cela tend à démontrer la synchronie entre les activités de production et d'utilisation des supports. Il nous paraît donc peu vraisemblable que les différents occupants du site aient réemployé des supports débités et abandonnés lors de passages précédents. La retouche des bords est dans la logique du schéma de production initial. Elle ne correspond pas à une réutilisation « opportuniste » de bords de lames anciennement débitées.

\section{Les premiers résultats}

\subsection{Les acquis de la tracéologie}

Une première analyse tracéologique réalisée à l'occasion du rapport de synthèse a concerné un large spectre d'outils et de pièces brutes. Marianne Christensen a ainsi analysé près de 800 pièces, outillage comme supports présentant un «bord » potentiellement utilisé. Cent quatrevingt pièces ont fourni un résultat positif (Christensen in Bodu, 1995, 1998b).

Les premières conclusions générales émises par Marianne Christensen, mettaient en avant la relative polyvalence de l'outillage commun, tant dans son monde d'utilisation que par les matières d'œuvres travaillées. Cette polyvalence se caractérise, par exemple, par l'utilisation des grattoirs sur des matières d'œuvres aussi diverses que la peau, les végétaux et les matières dures animales (locus 4). Au sein du même locus 4, les burins semblent très spécialisés dans le travail des matières dures animales ce qui n'a rien d'étonnant, alors que des fragments de bois de cervidé ont été retrouvés dans l'unité. Les bipointes ont, quant à elles, presque exclusivement fonctionné comme armatures de projectiles axiales. Des traces d'oxyde de fer (magnétite) ont également été localisées sur certaines parties actives d'outils (fronts de grattoirs et biseaux des burins), sans qu'il soit possible d'affirmer la fonction de cette matière : poudre pour le travail final d'assouplissement de la peau ? Liant dans un adhésif d'emmanchement ? La présence de ce matériau sur une bipointe du locus 46 accrédite sérieusement cette seconde hypothèse sans exclure une utilisation autre.

Les traces identifiées sur les outils indiquent un important travail des matières dures animales, alors même que ne sont connus que trois poinçons en os (Fig. 7) pour tout le niveau inférieur ainsi que quelques fragments de bois de cervidé (locus 4) et qu'un métacarpien de lion porte une trace de sciage (Fig. 7) (Bodu et Bemilli, 2000). Le travail des peaux est également important, tout comme les actions sur les matériaux végétaux (représentant jusqu'à $22 \%$ des traces d'utilisation pour le locus 4 !).

Pour les lames, les résultats évoquent également un spectre d'utilisation large et ubiquiste (Tableau 3) : travail de la peau (raclage essentiellement), découpe de viande et de végétaux, et sciage de minéraux. Les résultats, à ce niveau d'analyse, restent assez triviaux quoique beaucoup moins classiques en ce qui concerne les deux derniers matériaux.

\subsection{L'analyse du matériel}

Cela fait relativement peu de temps que l'étude des outillages préhistoriques a dépassé la description et l'énumération formelles des types, s'intéressant à présent, aux intentions qui guident la fabrication et l'utilisation des outils. Le concept de chaîne opératoire, s'il est appliqué 
Tableau 3

Résultats tracéologiques obtenus sur les lames utilisées brutes et retouchées du niveau azilien ancien du Closeau Use-wear results obtain on used and retouched blades from low level of Le Closeau

\begin{tabular}{lccc}
\hline & Corpus & Résultats tracéologique & $\%$ \\
\hline Locus 4 & & & \\
Retouches Marginales & 46 & 6 & 32 \\
Retouches Écailleuses-scalariformes & 37 & 12 & 32 \\
Locus 46 & 68 & 15 & 22 \\
Retouches Marginales & 61 & 10 & 16 \\
Retouches Écailleuses-scalariformes & & & \\
\hline
\end{tabular}

désormais de façon quasi systématique aux industries lithiques (Karlin et al., 1986), n'est pas encore suffisamment utilisé dans la compréhension des processus dynamiques relatifs à la conception et à l'usage des outils. C'est un constat assez réaliste pour le Paléolithique supérieur qui est curieusement moins vrai pour le Paléolithique moyen pour lequel différents auteurs se sont attachés à suivre l'évolution intrinsèque des différents outils pour mieux en comprendre les règles de fabrication et d'utilisation. C'est notamment le cas des bifaces et des racloirs (Lenoir, 1973 ; Lepot, 1993 ; Soriano, 2000 ; Bourguignon, 2001). Nous nous sommes donc inspirés de ces travaux, de leur méthodologie, pour tenter de mieux comprendre les lames retouchées du Closeau, qui, toute proportion gardée, sont apparentées aux racloirs moustériens, si ce n'est dans leur fonction, tout du moins dans leurs modalités et degrés d'affûtage. Au Closeau, nous nous sommes interrogés sur l'apparente diversité de l'outillage tranchant, en nous attachant à une description fine des stigmates liés aux activités de retouche et d'utilisation des supports. Deux catégories d'outils tranchants ont ainsi été distinguées.

\subsection{Des lames à enlèvements marginaux}

La première catégorie est composée de lames qui portent des enlèvements inframillimétriques discrets sur un ou deux bords, avec dans la quasi-totalité des cas une délinéation marginale, localisée sur une des parties d'un des bords (Fig. 8). La morphologie, la localisation et surtout la taille des enlèvements ne sont pas comparables aux retouches spontanées, telles que les a décrites M. Newcomer (Newcomer, 1976) (Fig. 9). L'utilisation de ces supports sur des matières d'œuvres variées peut expliquer la présence de ces stigmates sur les bords de lames. Ces objets s'apparentent aux outils tranchants du Magdalénien, des lames utilisées brutes, mais leurs stigmates rappellent également ceux observés sur certains exemplaires de lamelles à dos ${ }^{2}$ (lamelles à dos tronquées de la couche 9b de Saint-Thibaud-de-Couz; Philibert in Bintz, 1995). Ces lames brutes et ces lamelles à dos sont très clairement mises en relation avec les travaux de découpe des matières carnées, dans le cadre d'activités de dépeçage et d'extraction de la viande (Philibert, op. cit. p. 301).

\subsection{Des lames à retouches écailleuses et écailleuses-scalariformes}

La seconde catégorie de lames porte des enlèvements plus ou moins continus sur un ou deux bords (Fig. 10). L'ampleur et la régularité des enlèvements sont autrement plus importantes que

\footnotetext{
${ }^{2}$ Pour ce dernier cas, nous n'excluons pas le fait d'une utilisation a posteriori d'éléments d'armatures.
} 

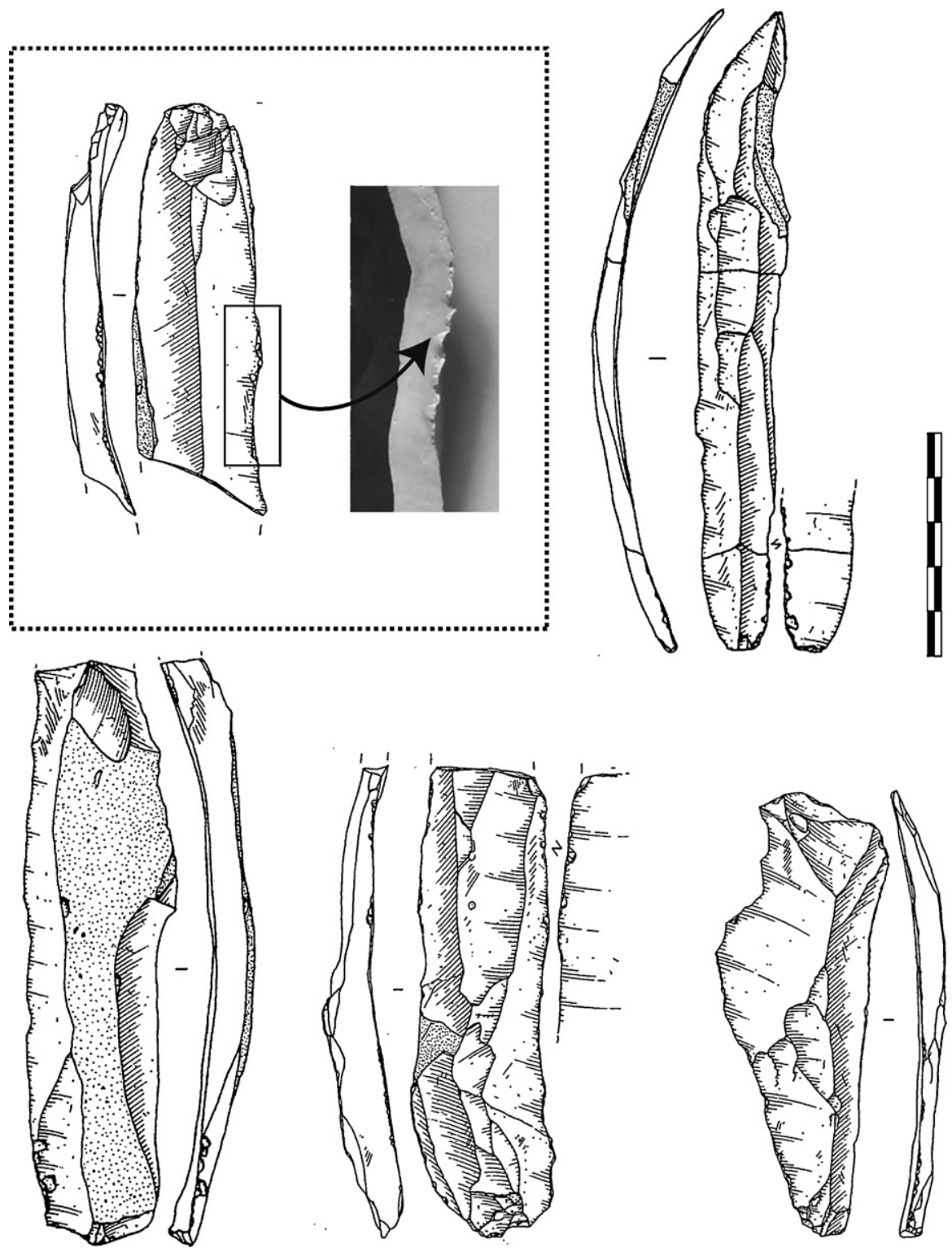

Fig. 8. Lames à enlèvements marginaux du niveau azilien ancien du Closeau (dessins : Ph. Alix ; Photo : L. Mevel). Blades edges with marginal retouches from the early Azilian level of Le Closeau (drawing: Ph. Alix; Photo: L. Mevel).

ce que l'on peut observer dans la catégorie précédente, ce qui permet d'évacuer l'hypothèse d'une simple utilisation de l'outil sur une quelconque matière d'œuvre. Les enlèvements présentent les critères « classiques » de la fracture conchoïdale (contre bulbe quand il est présent, ondulations sur le négatif de retouche, lancettes). Il s'agit donc de lames retouchées intentionnellement. 


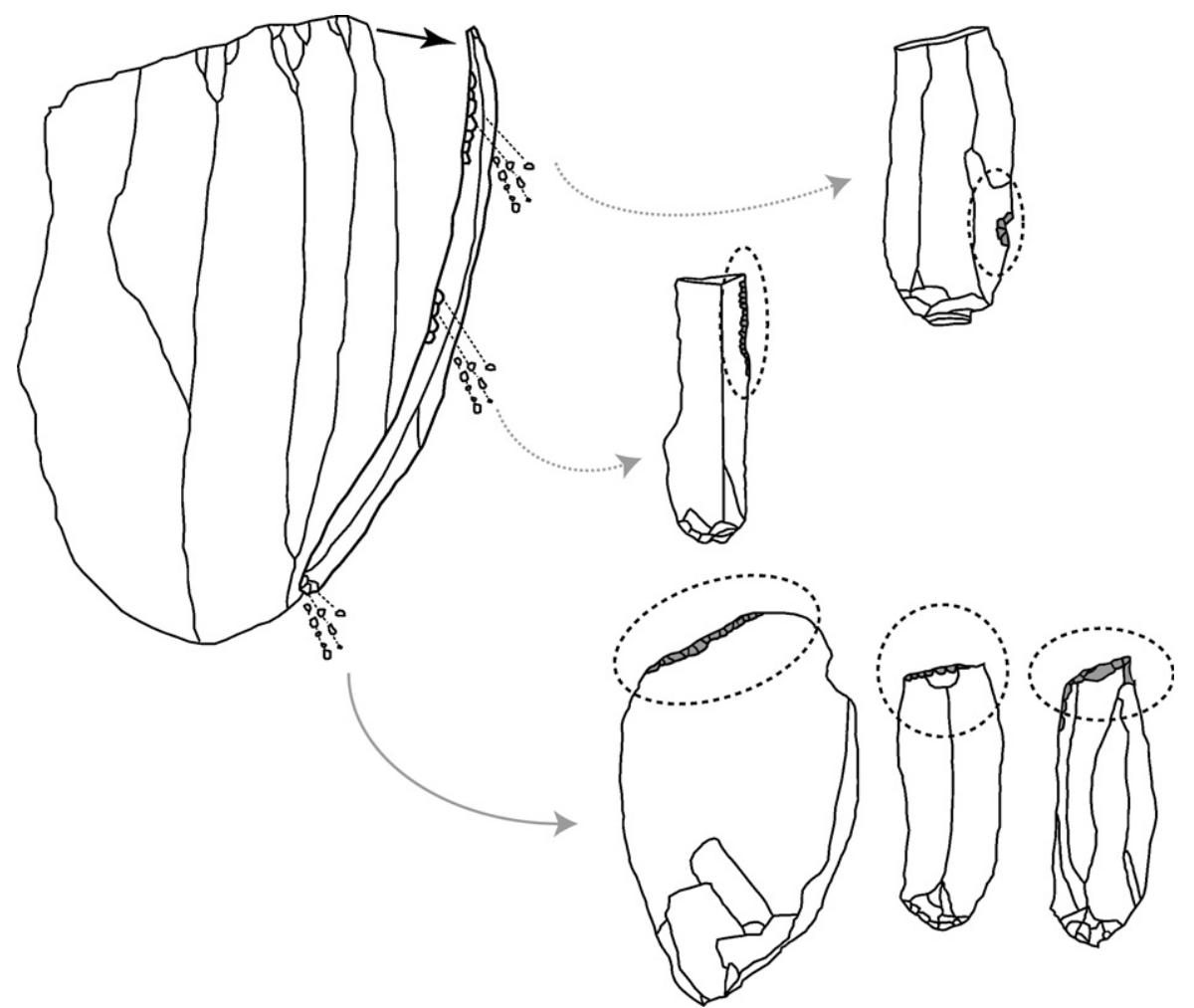

Fig. 9. La retouche spontanée : un accident récurrent sur les pièces archéologiques (d'après Newcomer, 1976, modifié).

Spontaneous retouch: a recurrent accident on archaeological lithic artifacts (after Newcomer, 1976, modified).

Ainsi, deux catégories d'objets tranchants, distincts par la présence ou non d'un aménagement de leurs bords, et peut-être par leur fonction, coexistent dans le niveau ancien du Closeau. La tracéologie a, par ailleurs, montré que ces deux « familles » ont fonctionné comme outils sur des matières d'œuvres variées. Cette distinction s'observe-t-elle à d'autres niveaux ? Dans les deux cas, les produits laminaires retenus sont des éléments de premier choix mêlés à quelques éléments de second choix (Fig. 11). La sélection des supports s'est opérée sur une large gamme dimensionnelle, avec une nette préférence pour des lames assez larges (comprise entre 18 et $28 \mathrm{~mm}$ ). Il existe, de même, une grande homogénéité des angles des bords des supports laminaires (appelés angles initiaux) compris entre $35^{\circ}$ et $50^{\circ}$ (Fig. 12). Ce sont, en revanche, les lames les plus régulières qui portent une retouche intentionnelle sur un ou deux bords.

C'est sur ces objets en particulier que nous allons nous attarder. Après une description plus fine des stigmates, nous nous interrogerons sur l'intention et l'objectif de cette transformation des supports. Il sera alors possible de confronter nos résultats à ceux de la tracéologie. Enfin, une approche expérimentale autour du mode d'obtention de ces retouches viendra enrichir le débat sur plusieurs interrogations nées des différents travaux menés autour de ces lames. 

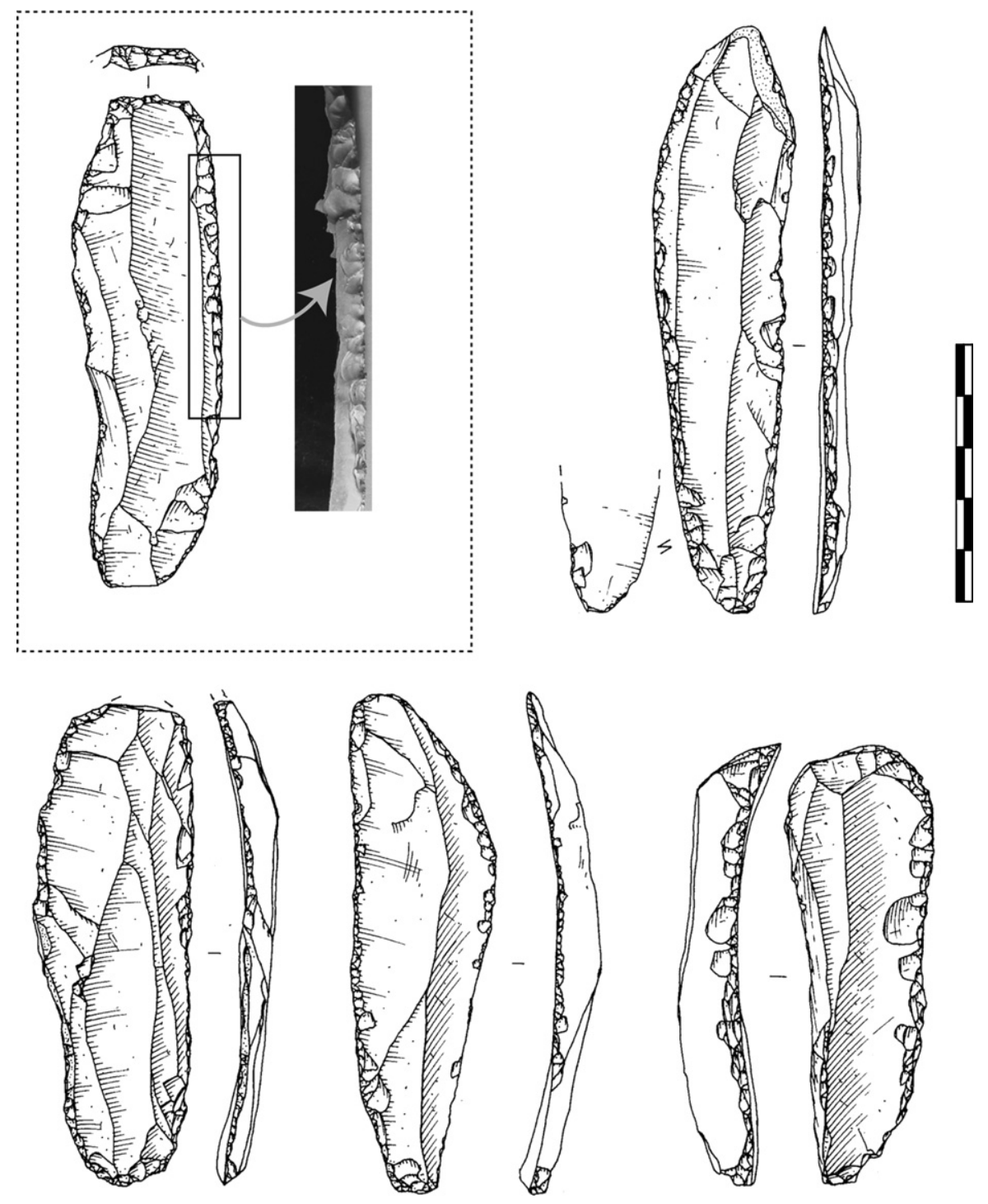

Fig. 10. Lames à retouches intentionnelles - Niveau azilien ancien du Closeau (dessin : Ph. Alix ; Photo : L. Mevel). Blades' edges with intentional retouches from the early Azilian level of Le Closeau (drawing: Ph. Alix; Photo: L. Mevel).

\section{Les lames retouchées intentionnellement : outils spécialisés et/ou châne de ravivage?}

Les lames retouchées sont au nombre de 94 pièces réparties à l'intérieur des deux principaux locus du niveau ancien, les locus 4 et 46 (Fig. 10). La plupart (65 pièces ${ }^{3}$ ) sont caractérisées par la

\footnotetext{
${ }^{3}$ Les pièces restantes correspondent à une plus grande diversité observée dans le locus 46, avec la présence de quelques lames appointées, denticulées, étranglées et à retouche abrupte de l'extrémité distale.
} 


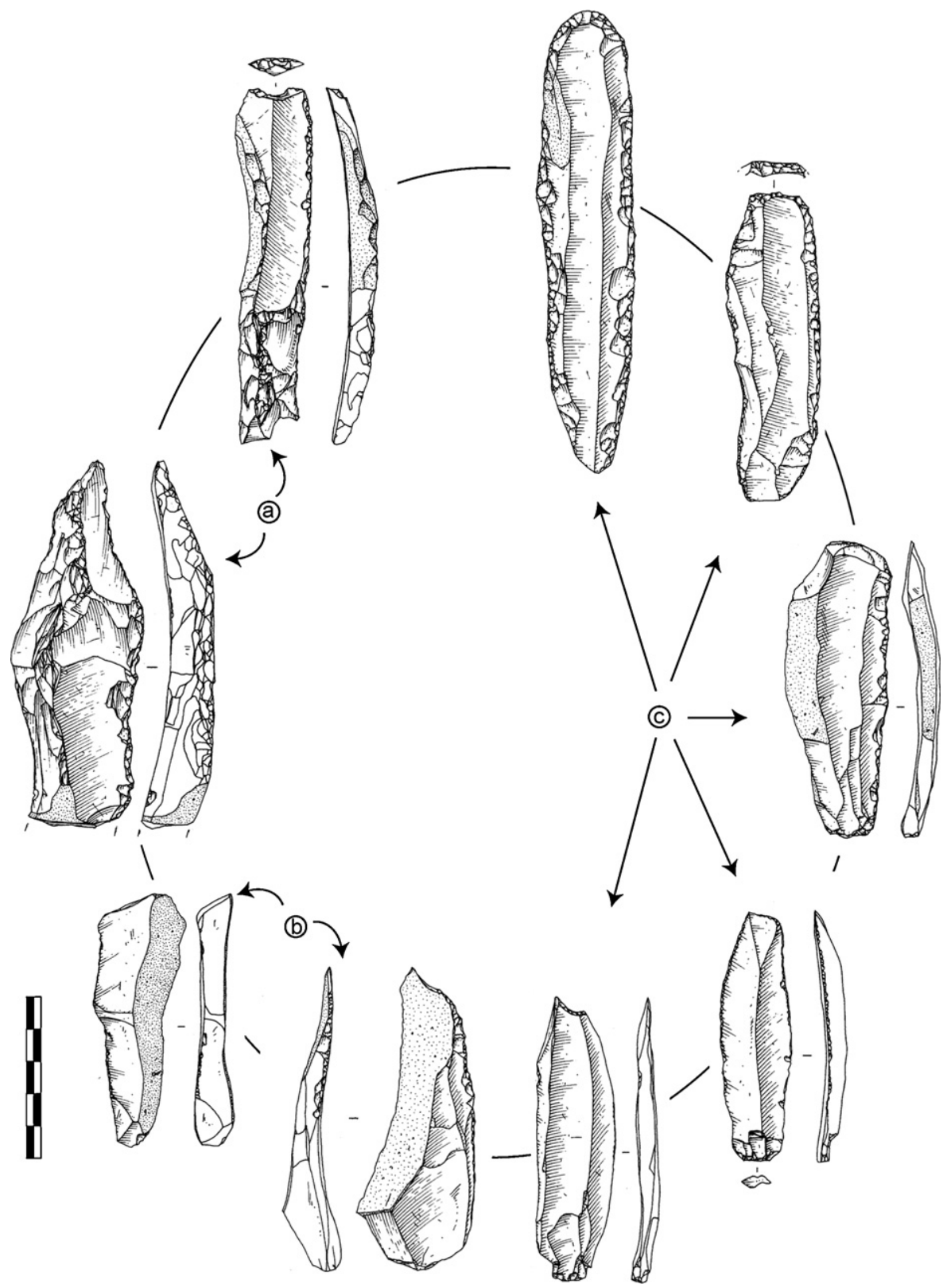

Fig. 11. Variété des supports laminaires retouchés et utilisés bruts. a. Lames à crête et néo-crête ; b. Lames semicorticales ; c. Lames de plein débitage (dessin : Ph. Alix).

Variety of blades used and retouched; $\boldsymbol{a}$. Crested blade; $\boldsymbol{b}$. Semi-cortical blade-like flake; $\boldsymbol{c}$. Blade from the "plein débitage" optimal phase (drawing: Ph. Alix). 


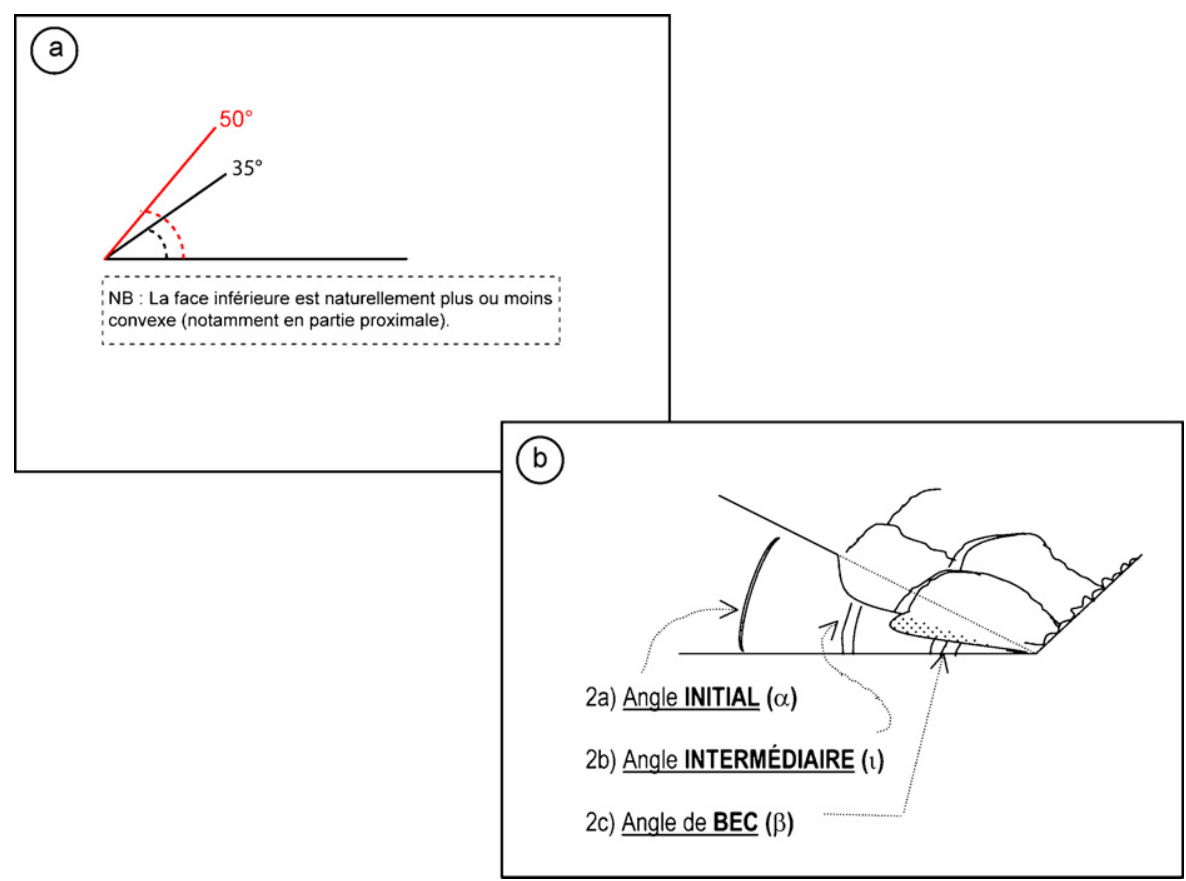

Fig. 12. a. Classes d'angles majoritairement recherchés (DAO : L. Mevel). b. Terminologie appliquée à la description d'un bord retouché (dessin : M. Lepot (d'après Boëda et al., 2003).

a. Major angles classes sought (CAD: L. Mevel). b. Terminology used for the description of a retouched edge (drawing: M. Lepot (after Boëda et al., 2003).

présence d'enlèvements très rasants localisés sur un ou deux bords du support. La retouche appliquée ici ne modifie pas l'angle de bec de la lame (Fig. 12). Ainsi, elle n'a pas pour vocation de modifier l'angulation du dièdre tranchant, mais plutôt de le raviver. Plusieurs degrés d'intensité de la retouche des bords ont été identifiés. Alors que sur une partie des lames on note la présence d'une seule ligne de retouches (24\% de l'ensemble des lames retouchées), sur d'autres supports, plusieurs séries d'enlèvements se succèdent (37\% de l'ensemble des lames retouchées) (Fig. 13). Quelle signification donner à ces différents états de retouche ? Est-ce que la succession des lignes de retouches participe au façonnage d'un outil à part entière, comme cela semble être le cas pour le processus d'aménagement des racloirs Quina (Bourguignon, 2001) ?

\subsection{Des lames à une seule ligne de retouche}

La retouche écailleuse simple (Fig. 13) se caractérise par des enlèvements rasants qui se développent sur une seule ligne de retouche. Les tranchants sont relativement émoussés, mais pas écrasés. Cette ligne de retouche est systématiquement recoupée par une ligne inframillimétrique, interprétée comme un stigmate d'utilisation de la pièce. L'angle initial des lames est compris entre 20 et $45^{\circ}$. Celui du dièdre tranchant obtenu après la série d'enlèvements (l'angle de bec) ne le modifie pas. C'est là la conséquence d'une recherche d'enlèvements très rasants pendant le processus d'aménagement. La caractéristique de cette retouche est justement de conserver l'angulation initiale du bord malgré son incidence. Dès lors, en amont de ce processus, la production comme la sélection des supports doivent être particulièrement calibrées. 

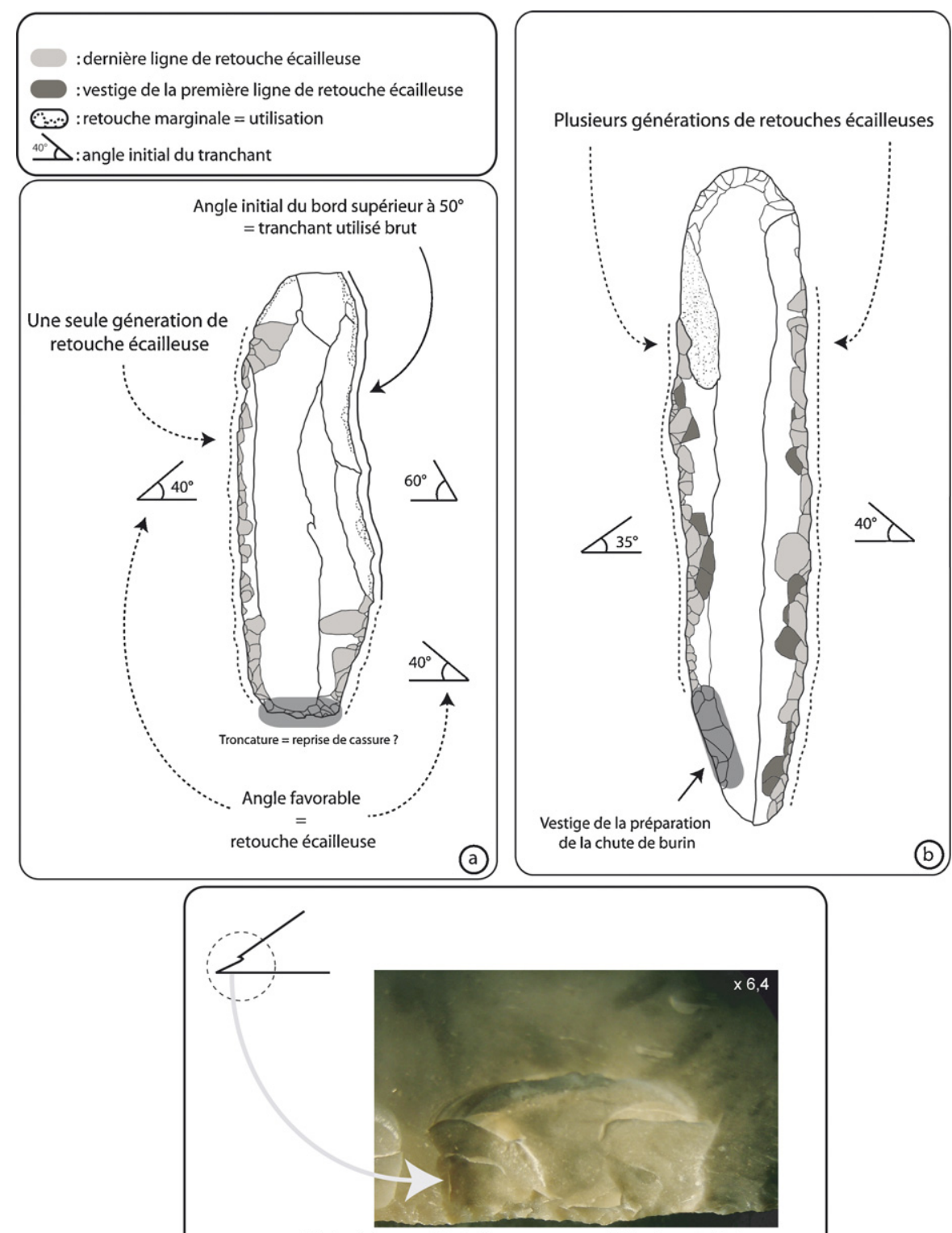

Fil de la lame vif et plan par rapport à la face infèrieure

(c)

Fig. 13. a, b. Deux intensités remarquables dans la retouche des fils de lames pour le niveau inférieur du Closeau (schéma : L. Mevel). c. Morphologie des tranchants retouchés recherchés au Closeau (photo : L. Mevel).

$\boldsymbol{a}, \boldsymbol{b}$. Two remarkable intensities on the blade's edge retouch for the lower level at Le Closeau (diagram: L. Mevel).

c. Retouched edge morphology sought after by the Azilians from Le Closeau site (photo: L. Mevel). 
$\mathrm{Si}$ on se réfère à l'exemple lointain des racloirs Quina, la retouche a pour objectif l'aménagement d'un dièdre différent de celui du support initial. Selon Laurence Bourguignon, cela est à mettre en parallèle avec les objectifs de production. La recherche des supports d'outils ne va pas de pair avec une recherche d'angles initiaux particuliers. Les tailleurs du Paléolithique moyen privilégiaient plutôt les éclats larges et épais sur lesquels la retouche Quina était plus aisée. L'intention générale sous-jacente n'est, en revanche, pas éloignée puisque cette dernière retouche a pour objectif ultime l'obtention de " dièdres précis » et vraisemblablement équivalents à tous les stades d'affûtages du racloir (Bourguignon, 2001).

Dans le cas du Closeau, la sélection des supports retouchés a autant privilégié leur morphométrie générale, que cette fameuse angulation initiale du dièdre tranchant. Cela est visible sur plusieurs supports, puisque la modification du tranchant n'est appliquée que sur des angles initiaux adéquats. La Fig. 13 montre que des portions de bords jugées trop obtuses par les artisans, n'ont pas fait l'objet d'une reprise du tranchant. Pour autant, le dièdre brut a pu être utilisé à un autre moment de l'histoire fonctionnelle du support. Si la délinéation des bords est aussi bien convexe que rectiligne, on note une légère prédominance des bords droits dans le locus 4 qui, à ce degré, d'observation n'est pas interprétable (30 sur 58 bords rectilignes pour le locus 46 , et 30 sur 35 pour le locus 4 ).

\subsection{Des lames à retouches écailleuses-scalariformes}

La retouche écailleuse-scalariforme correspond à plusieurs générations de lignes de retouches écailleuses (Fig. 13). La question principale était ici, rappelons-le, de s’interroger sur la relation entre ces objets et les lames à une seule ligne de retouche. Peut-on déceler une intention sousjacente différente dans l'aménagement du tranchant? Le type de retouche appliqué dans le cas de la retouche écailleuse scalariforme montre d'étroites similitudes avec ce que nous avons décrit pour la catégorie précédente. Les enlèvements sont toujours rasants, et visent pareillement à conserver l'angulation initiale du tranchant. Ce net rapprochement au niveau des intentions guidant les enlèvements de retouche, ainsi que les stigmates liés à ces derniers témoignent d'une véritable convergence technique entre les deux catégories de lames retouchées. Ainsi, la dernière ligne de retouche est un ultime réaménagement du bord de la lame, alors que les négatifs de retouche recouverts par cette dernière série d'enlèvements, correspondent au stade d'avivage antérieur.

La multiplication des lignes de retouche ne participe donc pas à la fabrication d'un outil particulier mais est la conséquence des différents avivages du tranchant (Fig. 14). Dans plusieurs cas, l'abandon final des lames à retouches écailleuses scalariformes a été motivé par une impossibilité technique à poursuivre l'avivage du tranchant, l'angle du dièdre ayant une nette tendance à devenir plus obtus à mesure que l'on multiplie les séries d'enlèvements. Les lames utilisées brutes, ont été affûtées, devenant ainsi des lames à retouches écailleuses qui, elles-mêmes, ont donné des lames à retouches écailleuses scalariformes.

Si les lames portant une retouche intentionnelle sont, pour le niveau ancien du Closeau, le résultat d'une chaîne d'avivage et donc le témoignage de la gestion économique particulière d'un outil pour le moins singulier, il n'en reste pas moins qu'il existe une bipartition assez nette entre des supports simplement utilisés bruts, et d'autres, beaucoup plus investis techniquement. À la lumière de ces résultats, la tracéologie semblait en mesure de nous préciser encore un peu mieux l'histoire particulière de ces outils. 

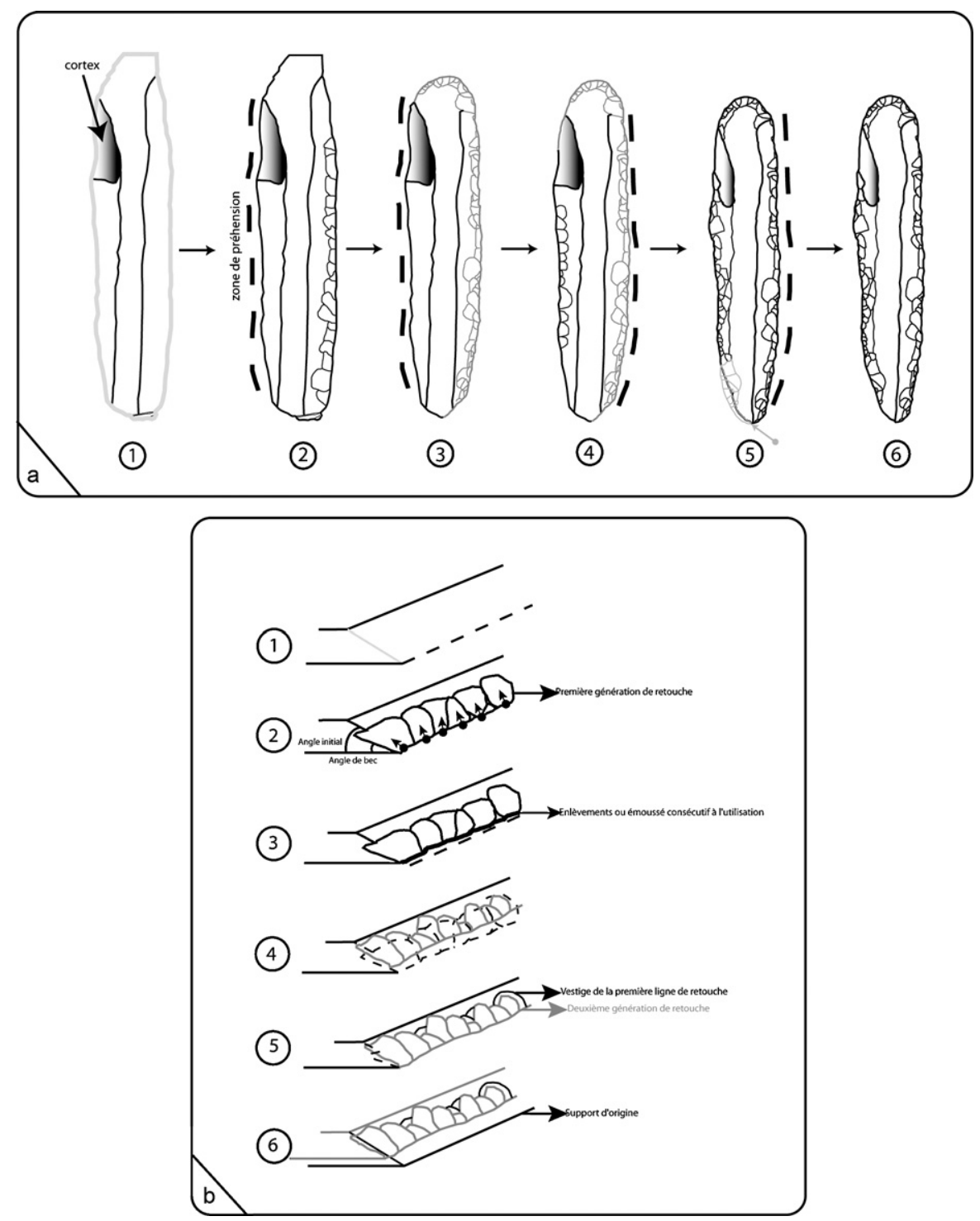

Fig. 14. a. Un exemple de l'utilisation d'un support laminaire en six étapes. (La question de la préhension du support n'est envisagée ici qu'en ce qui concerne l'utilisation des tranchants et non pas du front de grattoir). 1. Lame utilisée brute ; 2. Avivage d'un bord ; 3. Ravivage du bord/aménagement du grattoir (?) ; 4. Avivage du second bord ; 5 . Ravivage du second bord/préparation et extraction de la chute de burin ; 6. Abandon (DAO : Ludovic Mevel). b. Schéma technique d'obtention de la retouche écailleuse azilienne (DAO : Ludovic Mevel).

a. An example of blade blank use in six steps. (The issue of prehensility of the blank is here exclusively considered from the standpoint of edge use and not of end-scraper front). 1. Blade used unretouched; 2. Sharpening of an edge; 3. Resharpening of the edge/preparation of the end-scraper (?); 4. Sharpening of the second edge; 5 . Resharpening of the second edge/preparation and extraction of the burin spall; 6. Discard (CAD: Ludovic Mevel). b. Technical diagram showing how to obtain scaled and stepped retouch (CAD: Ludovic Mevel). 
Tableau 4

Résultats tracéologiques obtenus sur les lames à enlèvements marginaux $(\mathrm{X})$ et les lames retouchées $(\mathrm{O})$ - Locus 46 Use-wear results obtained on the blades with marginal removals $(X)$ and the blades retouched $(O)$ - Locus 46

\begin{tabular}{lllll}
\hline Action Matière d'œuvre & Transversale-raclage & Longitudinale-découpé & Longitudinale-sciage & Ind. \\
\hline Peau & XOOOOOOO & X & & \\
Tissu carne & & XXXO & & \\
Végétal & XXXX & & \\
Matières dures animales & $\mathrm{X}$ & & $\mathrm{X}$ & $\mathrm{X}$ \\
Bois & $\mathrm{O}$ & $\mathrm{O}$ & & \\
Minéral & XO & &
\end{tabular}

\subsection{Qu'apporte la tracéologie à la lumière de ces premiers résultats ?}

Dans le tableau ci-dessus (Tableau 4), on note, malgré le nombre réduit de pièces qui ont livré des traces, la nette répartition qui semble se dessiner entre les deux catégories définies précédemment. Les lames retouchées ont plutôt fonctionné dans le cadre d'un travail des peaux, en tout état de cause dans leur dernier état. Elles sont associées à un geste de raclage transversal. Les lames brutes semblent, quant à elles, avoir eu un spectre d'utilisation plus diversifié, qui n'inclut que très marginalement le travail des peaux. Elles seraient plus volontiers associées à un geste de découpe. Ces deux « outils » semblent donc se distinguer du point de vue de leur mode opératoire. Doit-on alors imputer au travail des peaux, le soin apporté à l'affûtage des tranchants des lames ? Si c'était le cas, cela signifierait que les Aziliens anciens opèrent différemment des magdaléniens, lors des travaux de peausserie, en tout cas lors de certaines opérations.

\subsection{La répartition spatiale des lames tranchantes}

C'est à l'intérieur des deux grandes unités du niveau inférieur, les locus 4 et 46, que sont localisées l'essentiel des lames à retouches marginales et des lames retouchées intentionnellement. Les différentes études déjà entreprises ont démontré que :

- l'essentiel des activités de boucheries ont été réalisées à l'intérieur des zones circonscrites par les blocs de pierre (Bignon in Bodu, 1998b, 2000) ;

- l'outillage portant des traces d'utilisation est également largement concentré à l'intérieur de ces zones (Christensen in Bodu, 1998b : p. 365, Fig. 15);

- les concentrations extérieures à la structure du locus 46 ont été interprétées comme des zones de dépotoirs ou des postes de tailles (Bodu, 1998b) (Fig. 15).

Les autres unités attribuées au niveau inférieur (locus 33, 56, 57, 58, 59) ont, en revanche, un fonctionnement plus spécialisé autour de la production de supports lithiques destinés à l'exportation (vers les autres locus ou à l'extérieur du site - Bodu et al., 2006a). Est-ce que la bipartition apparente d'ordre technique et fonctionnelle qui se dessine entre les « lames utilisées brutes » et les « lames affûtées » se traduit par une répartition spatiale particulière des artefacts ?

Les lames à retouches marginales et celles retouchées intentionnellement sont massivement localisées à l'intérieur des espaces structurés. On en retrouve également dans les zones de rejets adjacentes à ces structures (Fig. 16). À un degré d'analyse plus fin, on constate que : 

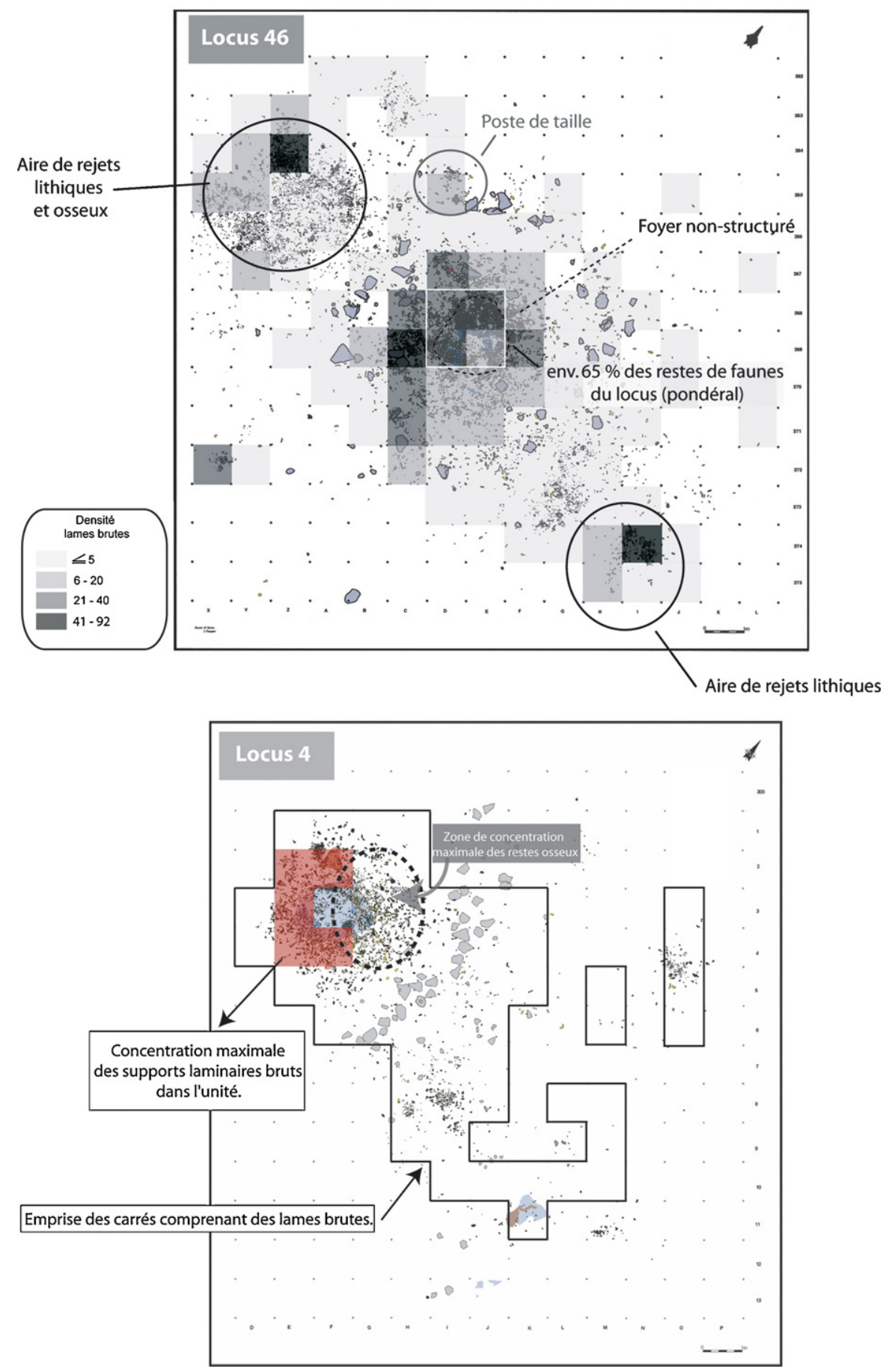

Fig. 15. Plan des locus 4 et 46 (DAO : Ludovic Mevel, d'après Bodu, 1998b ; Bodu et al., 2006). Distribution map from the loci 4 and 46 (CAD: L. Mevel, from Bodu, 1998b; Bodu et al., 2006). 


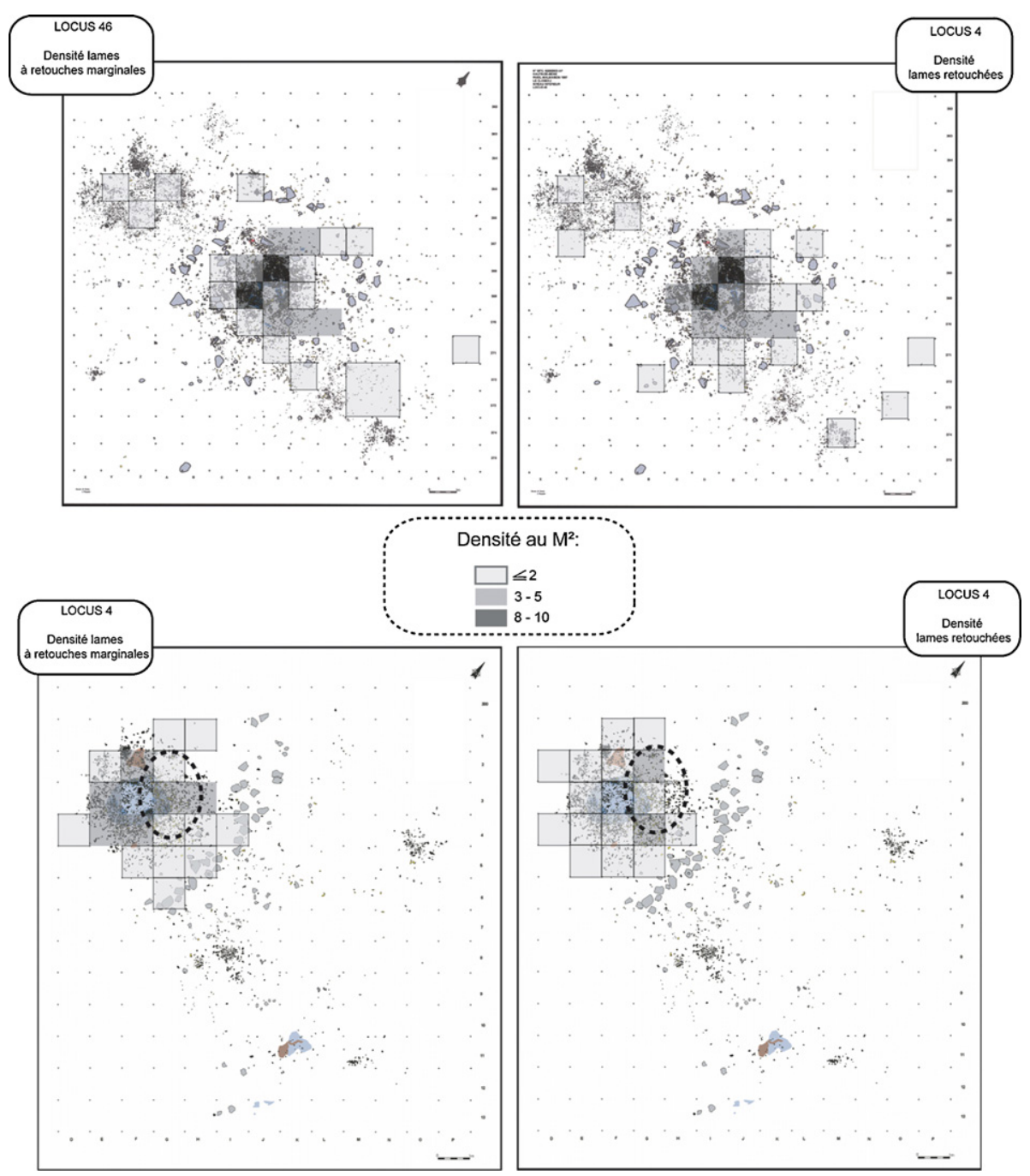

Fig. 16. Les localisations spatiales des lames retouchées et utilisées brutes au sein des locus 4 et 46 (DAO : Ludovic Mevel, d'après Bodu, 1998b).

Distribution map of marginal and intentionally retouched blades from the loci 4 and 46 (CAD: L. Mevel, from Bodu, 1998b).

- à l'intérieur du locus 46 , les plus fortes concentrations sont localisées à l'intérieur des mêmes carrés (Fig. 16). On notera que c'est la zone sud-ouest du foyer, qui recèle le plus grand nombre de lames utilisées brutes et retouchées. Pour autant, peut-on dissocier à l'intérieur de la structure une zone de rejet (ouest) et une zone d'activité (est) ? Rien n'est moins sûr ;

- pour le locus 4 , les lames utilisées brutes sont réparties de manière assez égale tout autour du foyer (Fig. 16). On remarquera que les concentrations de lames retouchées sont proches de la zone de forte densité de vestiges osseux. Comme pour le locus 46, nous serions tentés de distinguer deux espaces à l'intérieur de la structure : une zone de rejet où sont concentrés l'essentiel des déchets lithiques (est) et une zone d'activité principale où on retrouve les 
vestiges osseux (ouest). Mais comme pour le cas précédent, il nous faut admettre qu'il est difficile d'être affirmatif.

Dans la mesure où les lames à retouches intentionnelles et celles utilisées brutes ont un pan d'histoire commune, il n'est guère surprenant de les retrouver dans les mêmes secteurs à l'intérieur des espaces structurés. Les carrés où on retrouve des éléments retouchés sont très rarement dénués de pièces brutes portant des stigmates d'usage. Est-ce pour autant la démonstration d'une utilisation «synchrone » de ces outils au sein d'un même espace de travail ? La répartition des vestiges montre à l'évidence que les activités liées à l'utilisation de ces outils se sont déroulées à l'intérieur de la structure. Une interprétation plus fine des événements reste difficile à argumenter en l'état actuel des recherches. Cette difficulté tient sans doute à la réoccupation des structures par les Aziliens et au brouillage de l'occupation de l'espace que cela a généré (Bignon et Bodu, 2006).

\section{Synthèse des résultats}

Malgré le faible effectif de lames portant encore des traces d'utilisation, on ne peut que constater une certaine dualité fonctionnelle liée à l'intensité de la retouche. Les lames à retouches rasantes pour le travail de la peau et des lames à retouches marginales pour la découpe de la viande, et dans une moindre mesure le travail de la peau et des végétaux. D'où l'idée que la retouche rasante des bords sert à rendre à nouveau opérants des tranchants usagés pour un travail spécifique des peaux. Est-ce un moyen de rentabiliser des supports laminaires préalablement utilisés à d'autres fins ? Cela est probable au vu du nombre important de pièces retouchées après une utilisation brute (Christensen in Bodu, 1998b).

Le rôle de ces lames apparaît à peu près évident et leur intégration aux activités développées sur place tout autant. La spécificité des bords retouchés de l'Azilien ancien par rapport à ceux des lames du Magdalénien pose la question de leur rôle de marqueur culturel fort, au même titre que les pointes à dos. S'agit-il d'un outil spécialisé dans le travail des peaux ? Peut-être, mais alors pourquoi n'apparaîtrait-t-il pas chez les magdaléniens où l'on a aussi travaillé la peau et souvent celle du cheval, animal prépondérant au Closeau (Bodu et al., 2006b ; Julien et Rieu, 1999). Et même si cette retouche n'était que la résultante d'un affûtage des tranchants, on comprend mal pourquoi elle n'a pas été utilisée durant le Magdalénien alors qu'on y a, dans certains contextes, rentabilisé les supports.

Un début d'explication pourrait venir du fait que les lames sont plus plates et plus larges au Closeau et permettraient l'affûtage alors que les lames de section plus obtuse du Magdalénien autorisent moins ce type de retouches rasantes. Ce qui est vrai pour les lames de plein débitage magdaléniennes, l'est, en revanche, moins pour les lames d'entretien, plus plates et donc susceptibles d'accueillir ce type de retouche. Celle-ci pourrait être alors une conséquence de l'usage de la pierre tendre dans le débitage laminaire azilien qui donne, en effet, des supports aux pans moins aigus. La fonction du gisement ne peut, en tout cas, expliquer à elle seule la présence de ces lames retouchées, puisqu'elles existent la plupart dans des gisements attribués à la phase ancienne de l'Azilien. On pense, notamment, ici à la couche 4 de la grotte du Bois-Ragot dans la Vienne, où Boris Valentin a dénombré environ 80 lames à retouche écailleuse (Valentin in Chollet et Dujardin, 2005) (Fig. 17). Les couches 4 sup. (Magdalénien terminal/Azilien ancien) et 3b (Azilien ancien) du Pont d'Ambon en Dordogne contiennent chacune, une vingtaine de lames retouchées (Célérier, 1993 ; Célérier et al., 1997) (Fig. 17). Pour l'abri de La Fru en Savoie (Pion et al., 1990 ; Pion, 1997 ; Mevel et Bressy, sous presse), l'analyse de l'industrie azilienne 


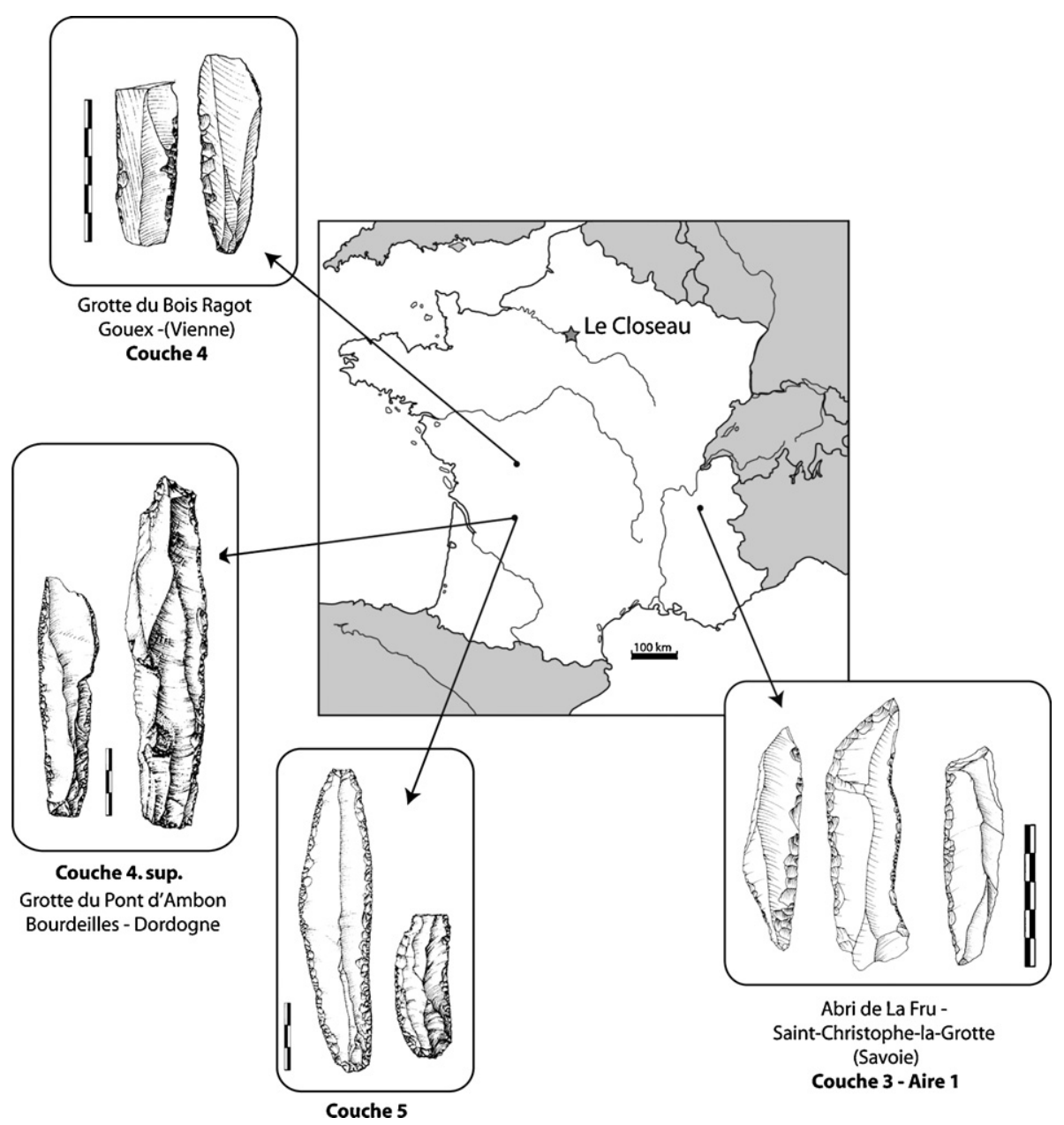

Fig. 17. Carte figurant les principaux sites présentant un ou plusieurs niveaux archéologiques attribués à la phase ancienne de l'azilien où des lames retouchées sont représentées (dessins d'après Chollet et Dujardin, 2005 ; Célérier, 1993 ; Mevel et Bressy (sous presse)).

Map showing the main sites with one or more archaeological levels attributed to the early phase of the Azilian where retouched blades are present (drawing from: Chollet and Dujardin, 2005; Célérier, 1993; Mevel and Bressy (in press)).

actuellement en cours, a confirmé leur présence dans les deux locus où ont été identifiés par Gilbert Pion des niveaux d'occupation attribuables à la phase ancienne de l'Azilien (couche 3 de l'aire 1 et couche 3 de l'aire 2) (Fig. 17). On en dénombre 32 pour la couche 3 de l'aire 1 et 25 pour la couche 3 de l'aire 2. À la différence du Closeau, à la Fru, l'obtention des supports laminaires sélectionnés pour être retouchés n'est clairement pas l'objectif prioritaire des activités de production. Les Aziliens ont plus volontiers utilisé des supports de second choix. La production s'attache ici à la recherche de petites lames calibrées pour la confection des bipointes. Cela est sans aucun doute à mettre en parallèle avec la fonction du site pendant la phase ancienne de l'Azilien, considéré comme une halte de chasse de courte durée.

Le statut particulier des lames retouchées au sein du système techno-économique des Aziliens, est confirmé par certains exemplaires. À La Fru (Pion et al., 1990 ; Pion, 1997 ; Mevel et 
Bressy, sous presse), elles ont parfois été réalisées sur des lames issues de silex affleurant à $80 \mathrm{~km}$ du site. Au regard de l'ensemble du corpus de lames retouchées, celles en silex exogène, ont été très clairement les plus intensément avivées. C'est sans aucun doute le témoignage d'une durée de vie importante de ces outils, dont l'apparente spécialisation fonctionnelle entrevue au Closeau, ne peut totalement exclure une plus grande polyvalence dans d'autres contextes. Surtout si on ne peut plus directement faire le lien entre leur lieu de production et celui d'abandon !

\section{Vers l'expérimentation}

La particularité de la retouche des lames de l'Azilien ancien a attiré notre attention et nous a incité, comme on l'a vu précédemment, à bien la décrire, et dans un second temps à tenter de la reproduire. Nous appuyant, en effet, sur des exemples lointains (retouche Quina ou retouche écailleuse aurignacienne), nous avons développé un protocole expérimental destiné à caractériser la technique d'obtention de ces retouches rasantes du bord après altération du tranchant initial.

Si nous avons fait assez peu varier les gestes et l'inclinaison du support (une retouche rasante ne peut s'obtenir qu'avec une inclinaison de la pièce oblique dans la main du tailleur et par un geste qui accroche tangentiellement le bord du support) (Fig. 18), nous avons testé la retouche avec différents types de percuteurs (bois végétal, bois animaux, os, percuteurs de pierre tendre) (Fig. 19). La pierre dure était d'emblée incompatible avec les traces observées sur le matériel archéologique comme nous avons pu le confirmer lors de l'expérimentation. La technique mise en œuvre a été presque exclusivement la percussion directe. Nous avons testé une retouche par pression, mais l'écart entre les résultats obtenus par cette technique et les traces archéologiques nous a convaincu d'éliminer cette dernière des prétendants à la retouche.

\section{Un percuteur/retouchoir plutôt tendre, oui mais lequel ?}

La percussion tendre organique a montré toute son efficacité tant au niveau des types d'enlèvements provoqués qui s'apparentent très étroitement à ce que l'on observe sur le matériel archéologique (enlèvements parfaitement rasants), qu'en ce qui concerne le rafraîchissement des

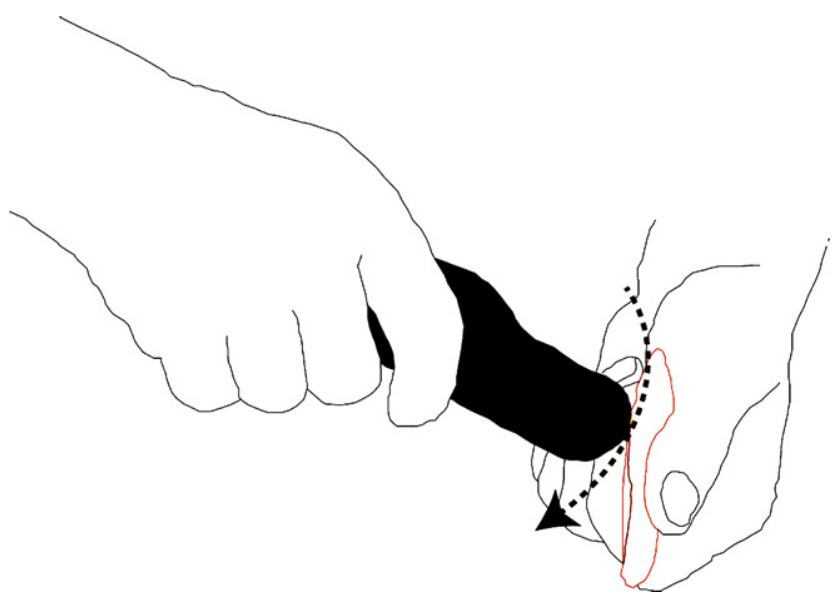

Fig. 18. Geste de percussion employé et position du support à retoucher (DAO : L. Mevel). Percussion gesture applied and position of the blank to be retouched (CAD: L. Mevel). 


\section{Retouchoirs / percuteurs existant \\ en contextes archéologiques \\ "contemporains" du niveau inférieur du Closeau}
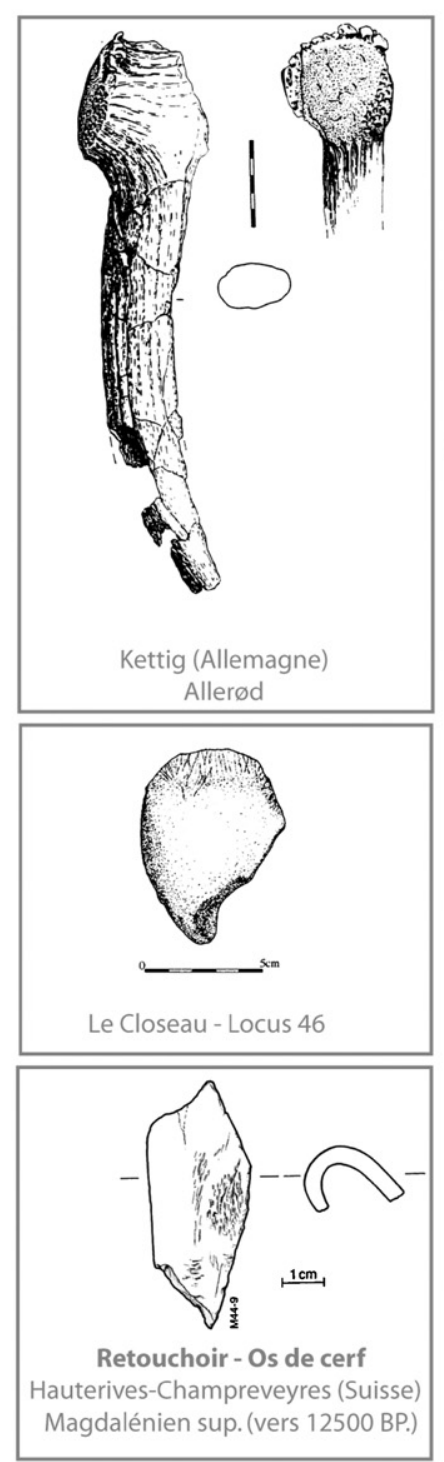

N'existe pas en contexte archéologique

\section{Retouchoirs / Percuteurs utilisés au cours de l'expérimentation}

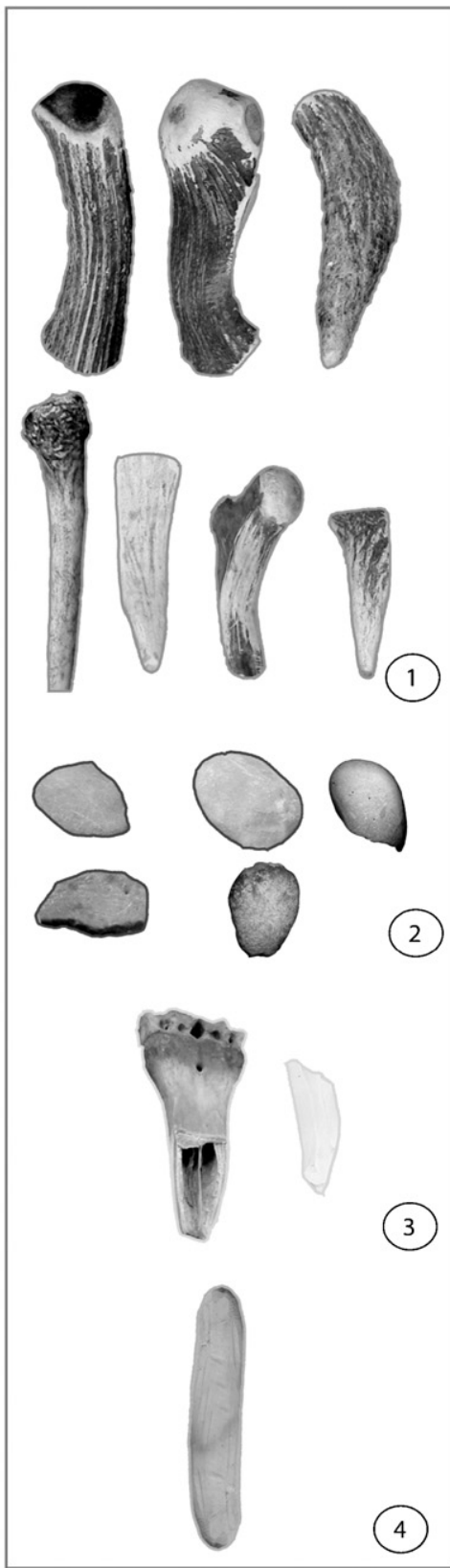

Fig. 19. a. Percuteurs et retouchoirs archéologiques tardiglaciaires (d'après Baales et Street, 1996 ; Bodu, 1998b ; Leesch et al., 2004). b. Variété des percuteurs expérimentaux utilisés (photos : P. Bodu/L. Mevel).

a. Late Glacial archaeological hammers and retouchers (from Baales and Street, 1996; Bodu, 1998b; Leesch et al., 2004). b. Variety of used experimental hammers and retouchers (photos: P. Bodu/L. Mevel). 


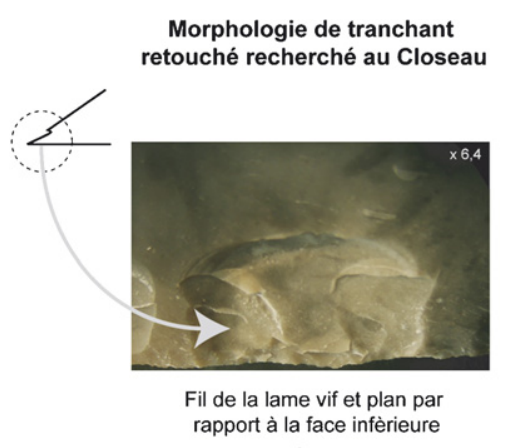

(a)

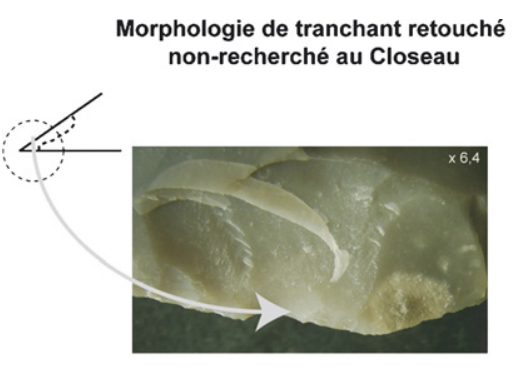

Dièdre du fil légèrement abrupte suite à l'outrepasssage du talon de l'éclat de retouche

(b)

Fig. 20. a. Morphologie des tranchants retouchés recherchée au Closeau (photo et DAO : L. Mevel). b. Morphologie de tranchant non recherché (photo et DAO : L. Mevel).

a. Edge morphology sought after by the Azilians from Le Closeau site (photos and CAD: L. Mevel). b. Edge morphology not sought after (photos and CAD: L. Mevel).

tranchants, puisque ceux-ci deviennent à nouveau coupants à l'issue de l'affûtage (Figs. 20 et 21). Les enlèvements provoqués ici ont permis d'obtenir des dièdres tranchants vifs et plans par rapport à la face inférieure du support. L'usage d'un percuteur tendre organique permet effectivement d'entretenir le fil coupant sans l'altérer. En revanche, aucun fragment d'os ou de bois animal présentant des stries compatibles avec une utilisation comme retouchoir n'a été identifié parmi les vestiges osseux du Closeau, qui serait comparable à l'exemplaire retrouvé dans le site Magdalénien du secteur 2 de Champréveyres (Fig. 19). Ce ne serait cependant pas la première fois que des percuteurs ou des retouchoirs organiques identifiés par les stigmates qu'ils ont laissés sur les artefacts lithiques, seraient absents des sites concernés. Il n'y a qu'à se tourner vers certains des grands gisements magdaléniens du Bassin parisien où la taille du silex revêt une importance certaine (Étiolles et Pincevent, par exemple : Pigeot, 2004 ; Bodu et al., 2006b) et où aucun percuteur tendre organique n'a été identifié, pour s'en convaincre !

À l'inverse, au Closeau, l'ensemble du débitage a été réalisé à la pierre tendre, sans doute en version tangentielle pour les lames. Ce sont les stigmates observables sur les nucléus et les produits débités qui permettent de diagnostiquer l'emploi de cette technique, technique confirmée par l'existence de quelques percuteurs en grès et calcaires dans les locus du niveau inférieur (Bodu, 1998b, Bodu, 1998b, 2000) (Fig. 22). Malgré un a priori défavorable concernant l'efficacité des percuteurs de pierre tendre dans la retouche rasante de bords de lames et nous appuyant sur les évidences archéologiques, nous avons donc testé cette hypothèse. Les premiers essais réalisés avec des matériaux calcaires et gréseux assez durs ont provoqué un certain nombre d'accidents que l'on ne retrouve pas sur le matériel archéologique. Outre une tendance à l'écrasement des bords (Figs. 20 et 21), ces percuteurs occasionnent de nombreux négatifs d'enlèvements outrepassant en partie proximale qui rendent le fil beaucoup moins tranchant. Mais, le geste appliqué ainsi que l'utilisation de l'arête naturelle des percuteurs, associés à une trop grande dureté des matériaux, sont vraisemblablement les causes principales de ce type d'accident. La présence au Closeau de percuteurs de pierre tendre de différentes duretés pouvait cependant laisser présager l'intégration de certains d'entre eux dans cette opération de retouche si particulière (Fig. 22). Un petit bloc de calcaire aux bords naturellement arrondis pesant environ $105 \mathrm{~g}$ a été découvert dans le locus 46 (F270.Tam) (Fig. 22). Il présente des stigmates caractéristiques (nombreuses stries et facettes sur la partie qui abrase, piquetage et esquillement 

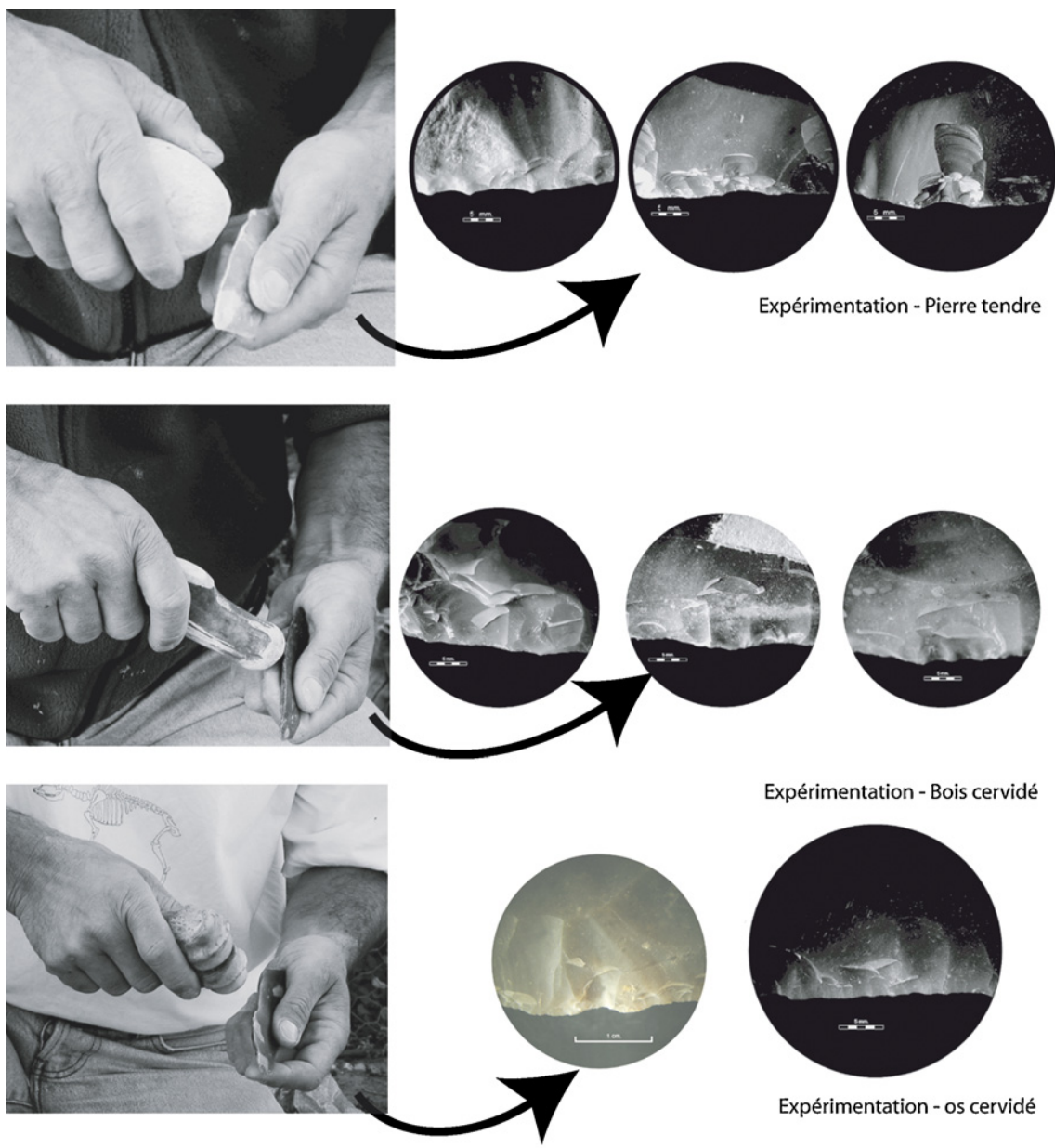

Expérimentation - Bois cervidé
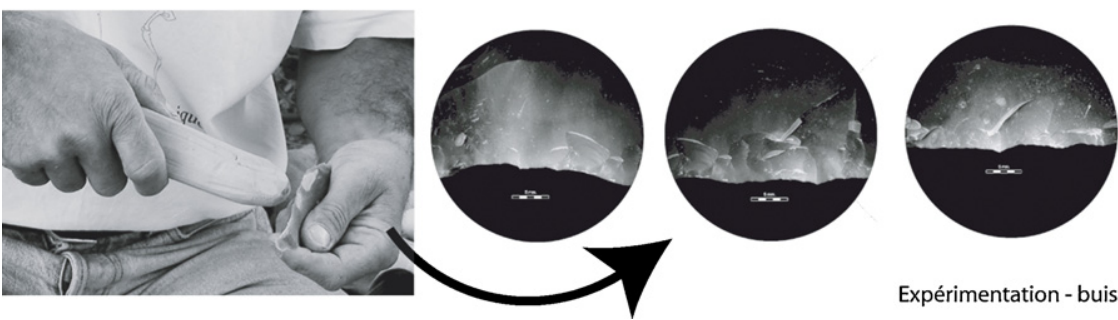

Expérimentation - buis

Fig. 21. Aspects des bords retouchés obtenus avec les différents percuteurs utilisés. Prises de vues réalisées sous loupe binoculaire. Grossissement 6,4 (photos et DAO : L. Mevel).

Aspects of the retouched edges obtained with the different hammers used. Photos achieved with binocular magnifying glass. Magnification 6.4 (photos and CAD: L. Mevel).

des arrondis qui ont percuté) qui témoignent de son utilisation comme percuteur/abraseur (Fig. 22). L'objet est discret et si une observation fine de sa surface n'avait pas permis d'identifier l'ensemble de ces stigmates, il aurait pu passer totalement inaperçu dans un contexte où des éléments de calcaire sont nombreux dans la nappe de graviers sur laquelle repose le site ! 

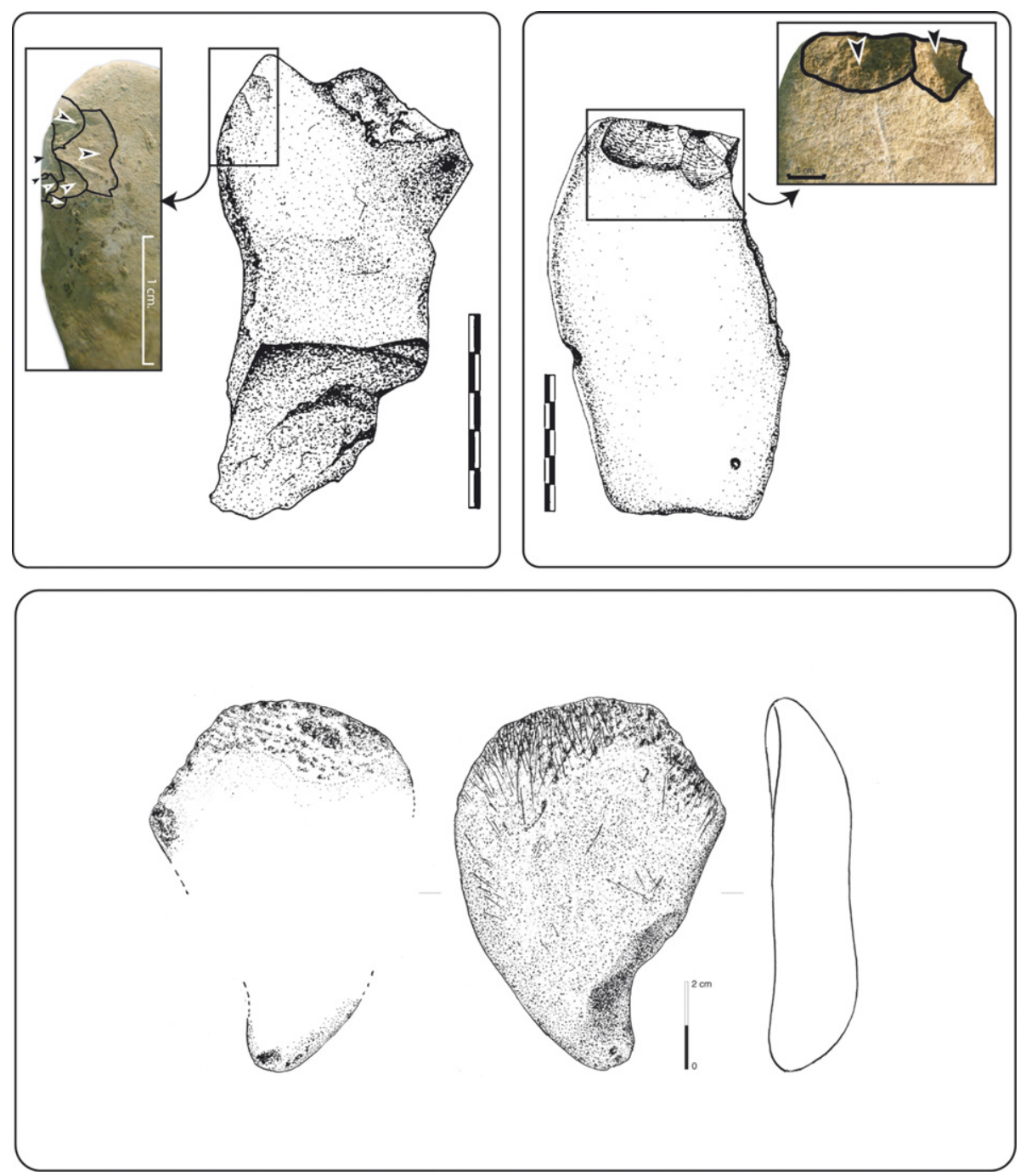

Fig. 22. Trois exemples de percuteurs en pierre tendre du niveau azilien ancien du Closeau (locus 46) (dessins : P. Bodu et D. Molez ; Cliché : Y.A. Gomez Coutouly ; DAO : L. Mevel).

Three examples of stone hammer from the early Azilian level - Le Closeau (locus 46) (drawing: P. Bodu and D. Molez; Photo: Y.A. Gomez Coutouly; CAD: L. Mevel).

L'identification de ce type de percuteur nous a incité à poursuivre l'expérimentation à l'aide d'un percuteur de pierre encore plus tendre que ceux employés précédemment (calcaire - $112 \mathrm{~g}$ ) (Fig. 23). Tout en conservant un geste très tangentiel, nous avons utilisé la face plane du galet. D'une part, le résultat obtenu s'approche très franchement de ce que nous avons pu obtenir avec du bois animal ou végétal, le tranchant étant parfaitement fonctionnel. D'autre part, on a rapidement observé des stigmates en tout point similaires à ce qui existe sur le « retouchoir » archéologique. L'hypothèse que nous proposons dès lors quant à l'outil qui a servi à rafraîchir le tranchant des lames, est celle d'une pierre tendre comparable dans sa dureté à l'objet trouvé dans le locus 46. 

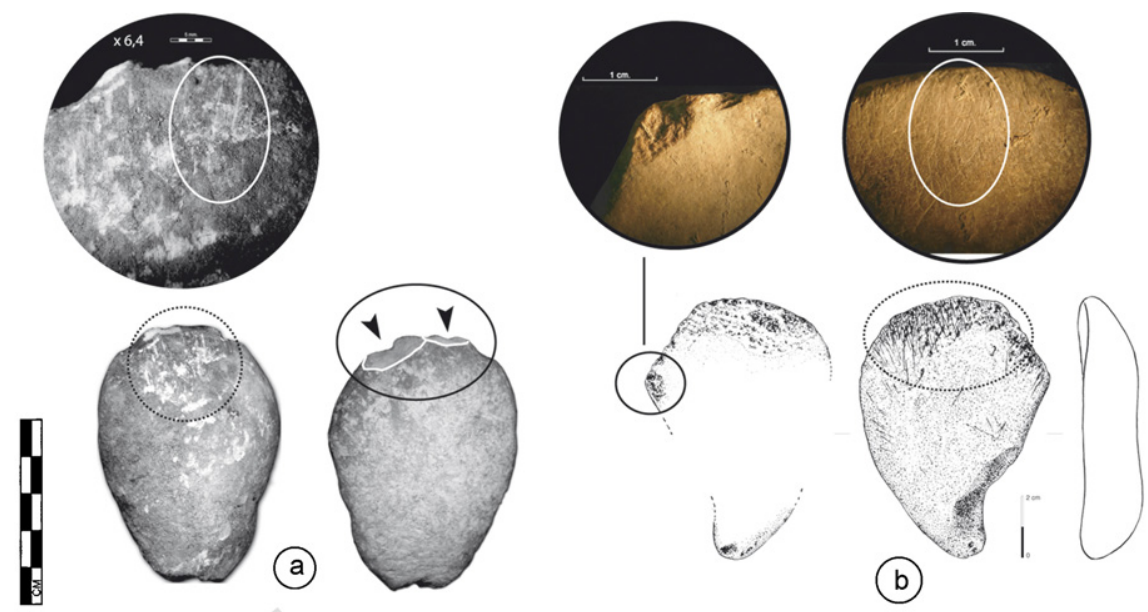

(b)

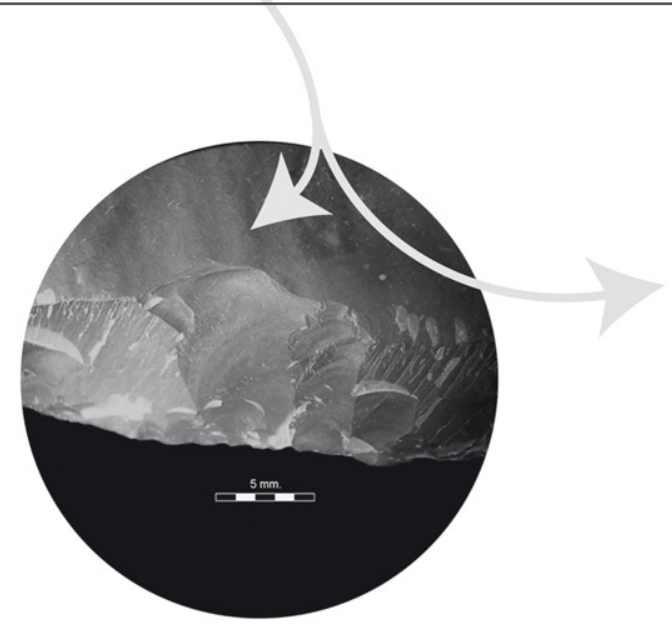

(c)
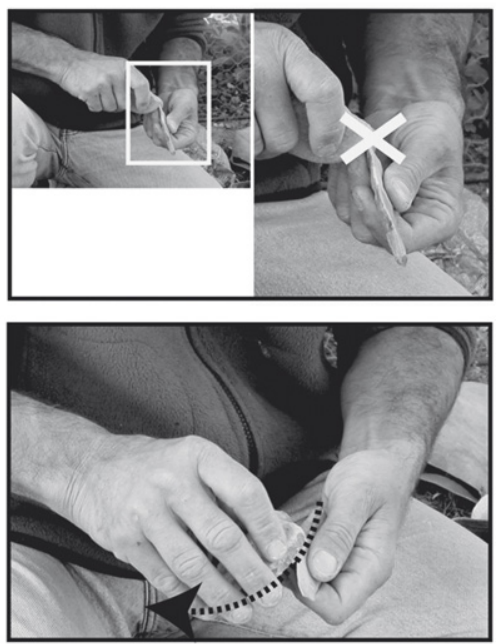

(d)

Fig. 23. Bords retouchés et pierre tendre : quelle relation ? a. Percuteur en calcaire expérimental. b. Percuteur en calcaire archéologique (Locus 46 - niveau inférieur du Closeau, dessin : D. Molez). Notez la convergence des stigmates et des cassures sur les deux percuteurs. c. Aspect du bord retouché avec l'utilisation de la face plane du galet (photo : L. Mevel). d. Geste et position du galet mis en œuvre pour l'obtention de la retouche rasante (photo : L. Mevel).

Retouched edges and soft stone hammer: What relation? a. Experimental limestone hammer. b. Archaeological limestone hammer (Locus 46 - lower level of Closeau, Drawing: D. Molez). Note the convergence of the characteristic elements and the breaking patterns on both hammers. . Aspect of the retouched edge using the plane surface of the pebble (photo: L. Mevel).d. Gesture and position of the pebble to obtain a low retouch (photo: L. Mevel).

\section{Conclusion}

En guise de conclusion, nous voudrions nous arrêter sur deux aspects distincts. D'une part, les types de percuteurs impliqués, d'autre part, le statut de la lame-couteau chez les Aziliens anciens. En ce qui concerne le premier aspect, on peut dire que si l'origine des enlèvements sur les lames du Closeau ne fait plus de doute, et qu'ils résultent d'une retouche volontaire, il y a un peu plus 

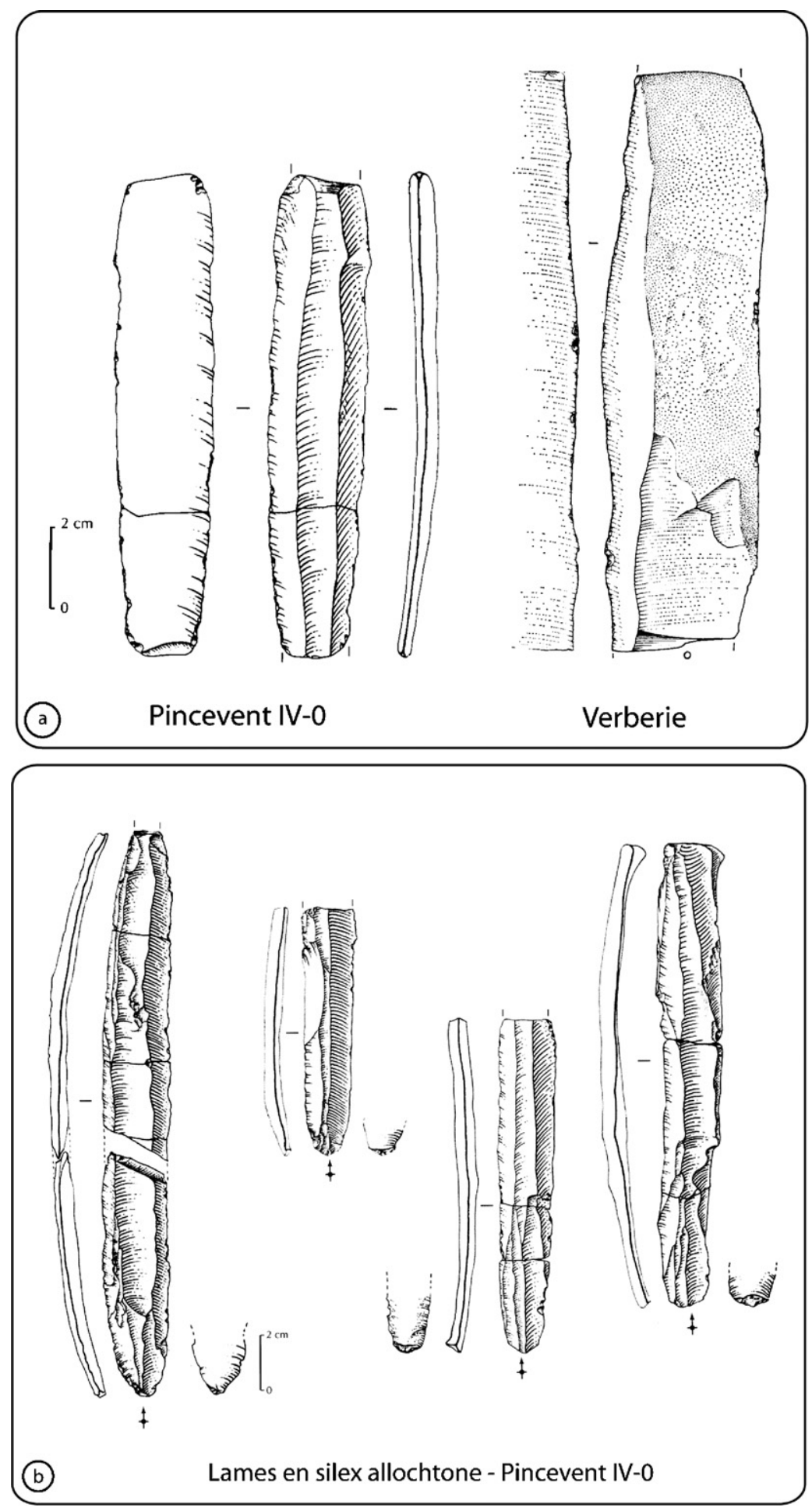
d'imprécision quant au type de percuteur impliqué : tendre certes, mais organique ou minéral ? La dernière expérimentation réalisée montre qu'une pierre très tendre peut jouer ce rôle de retouchoir, ce qui démontre très clairement que lorsque l'on parle de pierres tendres, on a tendance à globaliser alors que leurs variétés sont grandes. Cet exemple accroît les domaines d'action de la pierre dans les gisements du Paléolithique supérieur, alors que bien souvent les identifications de retouchoirs ou de percuteurs ne sont construites que sur des parallèles ethnographiques peu fiables ou des analyses tracéologiques insuffisantes, alors que leur contexte d'utilisation est insuffisamment documenté. Ici nous avons plusieurs acteurs de cette probable chaîne opératoire, ce qui renforce un peu nos hypothèses. Dès lors, si la pierre tendre est bien intervenue dans le processus d'affûtage des tranchants au Closeau, elle doit être traquée dans d'autres gisements contemporains, voire chronologiquement distincts où ce type de retouche des bords est identifié (Bourguignon, 2001). L'exemplaire du Closeau montre que l'on doit accorder de l'importance à des objets de pierre que l'on n'aurait pas, à première vue, classé dans la catégorie des percuteurs ou retouchoirs. Loin d'être anecdotique, cette problématique s'inscrit dans une démarche plus globale qui concerne les outils impliqués dans les débitages et la fabrication de l'outillage au Paléolithique supérieur.

Le second point de conclusion concerne la lame elle-même, lame tranchante, lame couteau. Au Closeau, mais aussi dans les rares autres gisements attribués à l'Azilien ancien, les lames retouchées correspondent donc à un type d'outil à part entière (Célérier, 1993 ; Célérier et al., 1997, Pion et al., 1990 ; Pion, 1997 ; Valentin in Chollet et Dujardin, 2005). Certaines de celles du niveau ancien du Closeau, les lames à retouches écailleuses ou écailleuses scalariformes témoignent vraisemblablement d'une longue durée d'utilisation scandée par un ou plusieurs moments d'affûtage. Les résultats tracéologiques montrent, par ailleurs, qu'elles sont impliquées dans une diversité d'activités, même si l'usage ultime a tendance à oblitérer les traces antérieures, les confinant dans un rôle lié au travail des peaux. Sur la lame retouchée azilienne, c'est le tranchant qui est privilégié, un peu comme on a favorisé l'aménagement et l'affûtage des tranchants sur les pièces solutréennes, pointes à face plane comme feuilles de laurier. De là à dire que les lames aziliennes ont un statut identique à celui du couteau du chasseur solutréen, il y a plusieurs pas que nous ne franchirons pas, mais cela nous amène à nous poser la question de l'absence « apparente » du couteau de chasse chez les magdaléniens (Fig. 24). En tout cas, il n'est pas investi du même soin que celui que l'on trouve sur les pièces solutréennes ou, dans une bien moindre mesure, sur certaines des lames du Closeau. Cela renvoie vraisemblablement au statut de l'objet lame dans les différentes sociétés paléolithiques, mais une raison plus simple peut également en expliquer la cause tout du moins partiellement : on ne traite là que de la lame en silex sans considérer son éventuel emmanchement. Peut-être que tout le soin apporté au couteau magdalénien se lit dans son manche!

\section{Remerciements}

A. Yan-Axel Gomez Coutouly pour la traduction du résumé et des légendes en anglais. A. Danièle Molez et à Gregory Debout pour l'emprunt de certaines illustrations.

Fig. 24. a. Deux exemples de lames utilisées brutes dans des contextes magdalénien supérieur du Bassin parisien : Pincevent IV-0 (Seine-et-Marne) (dessin : D. Molez) et Verberie (Oise) (d'après Audouze et al., 1981). b. Quatre lames en silex allochtone provenant du niveau IV-0 de Pincevent (Seine-et-Marne) (dessins : D. Molez).

a. Two examples of blades used unretouched in upper Magdalenian context in the Paris Basin: Pincevent IV-0 (Seine et Marne) (drawing: D. Molez) and Verberie (Oise) (After Audouze et al., 1981). b. Four unretouched blades in exogenous flint in IV-O level from Pincevent (drawing: D. Molez). 


\section{Références}

Audouze, F., Cahen, D., Keeley, L.-H., Schmider, B., 1981. Le site magdalénien du Buisson Campin à Verberie (Oise). Gallia Préhistoire 24, 99-143.

Baales, M., Street, M., 1996. Hunter-Gatherer Behavior in a Changing Late Glacial Landscape: Allerød. Archaeology in the Central Rhineland, Germany. Journal of Anthropological Research 52, 281-316.

Bemilli, C., 2000. Nouvelles données sur les faunes aziliennes du Closeau, Rueil-Malmaison (Hauts-de-Seine). In: Pion, G. (Éd.), Le Paléolithique supérieur récent : nouvelles données sur le peuplement et l'environnement. Actes de la table ronde de Chambéry, 12-13 mars 1999, Mémoire de la Société préhistorique française 28, Paris, p. 29-38.

Bignon, O., 2000. Analyse spatiale de la faune du site du Closeau (Hauts-de-Seine). Approche fonctionnelle et comportementale du locus 46. In: Boëda, É., Guillomet-Malmassari, V. (Éds.), Des comportements techniques dans la Préhistoire. Table ronde du laboratoire de Préhistoire et technologie, Ateliers 20, Labethno, Nanterre, pp. $207-237$.

Bignon, O., Bodu, P., 2006. Stratégie cynégétique et mode de vie à l'Azilien ancien dans le Bassin parisien : les apports de l'exploitation des chevaux du Closeau (niveau inférieur ; Rueil-Malmaison, Hauts-de-Seine). L'Anthropologie 110, 401-417.

Bignon, O., Enloe, J.G., Bemilli, C., 2006. Étude archéozoologique de l'unité T125 : originalité de la chasse des rennes et des chevaux. In: Bodu, P., Julien, M., Valentin, B., Debout, G. (Eds.), Un dernier hiver à Pincevent : les Magdaléniens du niveau IV0. Gallia Préhistoire 48, pp. 8-35.

Bintz, P. (dir.), 1995. Les grottes Jean-Pierre 1 et 2 à Saint-Thibaud-de-Couz (Savoie); Paléoenvironnement et cultures du Tardiglaciaire à l'Holocène dans les Alpes du Nord. $2^{\mathrm{e}}$ partie : la culture matérielle. Gallia Préhistoire 37, $155-328$.

Bodu, P., 1995. Le Closeau, Rueil-Malmaison (Hauts-de-Seine). AFAN, Document final de synthèse de diagnostic ( ${ }^{\text {er }}$ novembre 1994-15 janvier 1995). Direction Départementale de l'Équipement des Hauts-de-Seine, Service Régional de 1'Archéologie d'Île-de-France, Nanterre.

Bodu, P., 1998a. Magdalenians-Early Azilians in the centre of the Paris Basin: a filiation? The example of Le Closeau (Rueil-Malmaison, France). In: Milliken, S. (Ed.), The Organization of Lithic Technology in Late Glacial and Early Postglacial of Europe. BAR international series 700, Oxford, pp. 131-147.

Bodu, P. (dir.), 1998b. « Le Closeau », deux années de fouille sur un gisement azilien et belloisien en bord de Seine (RueilMalmaison, Hauts-de-Seine). AFAN, Document final de synthèse de sauvetage urgent. Service régional de l'Archéologie d'Île-de-France, 3 tomes.

Bodu, P., 2000. Que sont devenus les Magdaléniens du Bassin parisien ? Quelques éléments de réponse sur le gisement Azilien du Closeau (Rueil-Malmaison, France). In: Bodu, P., Christensen, M., Valentin, B. (Éds.), L’Europe centrale et septentrionale au Tardiglaciaire. Éditions APRAIF, Actes de la Table ronde internationale de Nemours (13-16 mai 1997). Mémoire du Musée de Préhistoire d'île-de-France 7, Nemours, pp. 315-339.

Bodu, P., Bemilli, C., 2000. Le gisement du Closeau à Rueil-Malmaison (Hauts-de-Seine) : le lion est-il mort ce soir ? In: Thévenin, A., Daubigney, A., Magny, M. et al. (Eds.), Les derniers chasseurs-cueilleurs d'Europe occidentale. Actes du colloque international de Besançon, 23-25 octobre 1998. Annales littéraires 699, Presses universitaires franccomtoises, Besançon, pp. 173-185.

Bodu, P., Debout, G., Bignon, O., 2006a. Variabilité des habitudes tardiglaciaires dans le Bassin parisien : l'organisation spatiale et sociale de l'Azilien ancien du Closeau. Bulletin de la Société Préhistorique Française 103, 711-728.

Bodu, P., Julien, M., Valentin, B., Debout, G. (Eds.), 2006b. Un dernier hiver à Pincevent. Les Magdaléniens du niveau IV0. Supplément à Gallia Préhistoire 48, 1-180.

Boëda, E., Lepot, M., Bonilauri, S., Mevel, L., 2003. Compte rendu de la Réunion Terminologie du 24 Mars 2003 : Approche techno-fonctionnelle (inédit).

Bourguignon, L., 2001. Apports de l'expérimentation et de l'analyse techno-morpho-fonctionnelle à la reconnaissance du processus d'aménagement de la retouche Quina. In: Bourguignon, L. (Ed.), Préhistoire et approche expérimentale. Collection Préhistoire, Éditions Montagnac 5, pp. 35-66.

Bricker, H.M. (dir.), 1995. Le Paléolithique supérieur de l'abri Pataud (Dordogne) : les fouilles de H.-L. Movius Jr : suivi d'un inventaire analytique des sites aurignaciens et périgordiens de Dordogne. Paris : MSH, 1995. DAF 50, 1-328.

Célérier, G. (dir.), 1993. L'abri-sous-roche de Pont d'Ambon à Bourdeilles (Dordogne). Gallia Préhistoire 35, 1-98.

Célérier, G., Chollet, A., Hantaï, A., 1997. Nouvelles observations sur l'évolution de l'Azilien dans les gisements de BoisRagot (Vienne) et de Pont-d'Ambon (Dordogne). Bulletin de la Société Préhistorique Française 94, 331-336.

Chaussé, C., 2005. Les horizons pédologiques tardiglaciaires du Closeau à Rueil-Malmaison (92). Premiers éléments de diagnose. In: Valentin, B., Bodu, P., Julien, M. (Éds.), Habitats et peuplements tardiglaciaires du Bassin parisien. Projet collectif de recherche 2003-2005. Bilan des activités de 2003 à 2005, Service Régional de l'Archéologie d'Îlede-France, pp. 87-93. 
Chollet, A., Dujardin, V. (dir.), 2005. La grotte du Bois Ragot à Gouex (Vienne) Magdalénien et Azilien. Essai sur les hommes et leur environnement. Mémoire de la Société Préhistorique Française 38, 1-427.

Fagnart, J.-P., Coudret, P., 2000. Le Tardiglaciaire dans le Nord de la France. In: Valentin, B., Bodu, P., Christensen, M. (Eds.), L'Europe centrale et septentrionale au Tardiglaciaire. Confrontation des modèles régionaux de peuplement. Nemours, Éditions de l'APRAIF, Mémoire du Musée de Préhistoire d'Île-de-France 7, p. 111-128.

Foucher, P., Normand, C., 2004. Étude des niveaux solutréens de la grotte d'Isturitz (Isturitz/Saint-Martin-d'Arberoue, Pyrénées-Atlantiques). Antiquités Nationales 36, 69-104.

Julien, M., Rieu, J.-L. (éd.), 1999. Occupations du Paléolithique supérieur dans le Sud-Est du Bassin parisien. Éditions de la Maison des Sciences de l'Homme, Documents d'archéologie française 78, Paris, 1-235.

Karlin, C., Pelegrin, J., Bodu, P., 1986. Processus techniques et chaîne opératoire : un outil pour le préhistorien. Bulletin de la Société Préhistorique Française 83, 66-67.

Leesch, D., Cattin, M.-I., Müller, W., 2004. Hauterive-Champréveyres et Neuchâtel-Monruz. Témoins d'implantations magdaléniennes et aziliennes sur la rive nord du lac de Neuchâtel. Archéologie Neuchâteloise 31, 1-237.

Lenoir, M., 1973. Obtention expérimentale de la retouche de type Quina. Bulletin de la Société Préhistorique Française 70. Actualité scientifique 10-11.

Lepot, M., 1993. Approche techno-fonctionnelle de l'outillage moustérien : Essai de classification des parties actives en termes d'efficacité technique. Application à la couche M2e sagittale du Grand Abri de La Ferrassie (fouille Delporte). Mémoire de Maîtrise, université Paris X-Nanterre, 2 volumes.

Leroi-Gourhan, A., Brézillon, M., 1966. L'habitation magdalénienne $n^{\circ} 1$ de Pincevent, près de Montereau (Seine-etMarne). Gallia Préhistoire 9, 263-371.

Leroi-Gourhan, A., Brézillon, M., 1972. Fouilles de Pincevent : essai d'analyse ethnographique d'un habitat magdalénien (la section 36). Supplément à Gallia Préhistoire VII 1-331.

Mevel, L., 2003. Des lames pourquoi faire ? L'exemple d'un gisement du Paléolithique supérieur final dans le Bassin parisien : Le Closeau à Rueil-Malmaison (Hauts-de-Seine). Article de DEA, université Paris-10-Nanterre.

Mevel, L., Bressy, C. (sous presse) Comportements techniques et économiques des groupes humains du Paléolithique final dans les Alpes du nord : l'exemple de l'Azilien ancien de l'abri de La Fru (Savoie). In: Pion, G. et Mevel, L. (dir.), La fin du Paléolithique supérieur dans les Alpes du nord, et le Jura méridional : approches culturelles et environnementales. Mémoire de la Société Préhistorique Française.

Mouton, P., Joffroy, R., 1957. Le gisement aurignacien des Rois à Mouthiers (Charente). 9e supplément à Gallia préhistoire, 1-140.

Newcomer, M., 1976. Spontaneous retouch. In: Engelen, E.F.G. (Ed.), Second International Symposium on Flint, Staringia 3, Nederlandse Geologische Vereniging, Maastricht, pp. 62-64.

Pigeot, N. (dir.), 2004. Les derniers Magdaléniens d’Étiolles. Perspectives culturelles et paléohistoriques. Supplément à Gallia Préhistoire XXXVII, 1-351.

Pion, G., 1997. L'abri de la Fru à Saint-Christophe (Savoie) : L'Azilien ancien du début de L'Allerød. Bulletin de la Société Préhistorique Française 94, 319-326.

Pion, G., Billard, M., Bintz, P., Caillat, B., Cataliotti-Valdina, J., Durand, J.-M., Girard, M., Monjuvent, G., 1990. L'abri de la Fru à Saint-Christophe (Savoie). Gallia Préhistoire 32, 65-123.

Schmider, B., 1971. Les industries lithiques du Paléolithique supérieur en Île-de-France. Supplément à Gallia Préhistoire VI 1-243 ( $2^{\mathrm{e}}$ édition, 1984).

Sonneville-Bordes, D. de, 1960. Le Paléolithique supérieur en Périgord. Éditions Delmas, Bordeaux, 2 volumes.

Soriano, S., 2000. Outillage bifacial et outillage sur éclat au Paléolithique ancien et moyen : coexistence et interaction. Thèse de l'université Paris-10-Nanterre. 